\title{
Tribofilm Formation, Friction and Wear-Reducing Properties of Some Phosphorus-Containing Antiwear Additives
}

\author{
Juli Felicio Luiz ${ }^{1} \cdot$ Hugh Spikes $^{1}$ (D)
}

Received: 22 April 2020 / Accepted: 21 June 2020 / Published online: 7 July 2020

(c) The Author(s) 2020

\begin{abstract}
The film-forming, friction and wear properties of a range of model and commercial ashless $\mathrm{P}$ and P/S antiwear additives have been studied. A method has been developed for removing the tribofilms formed by such additives in order to effectively quantify mild wear. In general the P/S additives studied formed thinner tribofilms but gave lower wear than the S-free $\mathrm{P}$ ones. In extended wear tests, three P/S additives gave wear as low, or lower, than a primary zinc dialkyldithiophosphate (ZDDP). For almost all lubricants tested the wear rate measured in short tests was considerably higher than that in long tests due to the greater contribution of running-in wear in the former. This highlights the importance of basing antiwear additive choice on reasonably long tests, where running-in becomes only a small component of the wear measured. It has been found that for both $\mathrm{P}$ and $\mathrm{P} / \mathrm{S}$ ashless additives the addition of oil-soluble metal compounds based on Ti and Ca boosts tribofilm formation and can lead to very thick films, comparable to those formed by ZDDP. However, this thick film formation tends to be accompanied by an increase in mixed friction and also does not appear to reduce wear but may even increase it.
\end{abstract}

Keywords Antiwear additive $\cdot$ Ashless additive $\cdot$ SAPS $\cdot$ Friction $\cdot$ Wear $\cdot$ Tribofilm

\section{Introduction}

Metal-free organophosphorus-containing compounds have been used as antiwear additives in aviation, transmission and hydraulic oils for many years. However, there is now considerable interest in employing them in crankcase engine oils, to replace, wholly or in part the currently used antiwear additive zinc dialkyldithiophosphate (ZDDP). This paper describes a study of the tribofilm-forming, friction and wear properties of a range of phosphorus- and phosphorus/ sulphur-based additives in rolling-sliding contact conditions. In all cases their performance is compared to that of a conventional ZDDP additive.

The aims of the study are twofold: firstly to assess the extent to which these additives can match the wear-reducing performance of ZDDPs in rolling-sliding contacts such as are present in sliding cam-follower components, and secondly to learn more about the nature of the tribofilms formed by these metal-free, ashless additives and thus how they

Hugh Spikes

h.spikes@imperial.ac.uk

1 Imperial College London, London, UK control wear. It should be noted that there is interest not just in seeking replacements for ZDDP but also to further understand the film formation, friction and wear performance of phosphorus-based antiwear additives in transmission oils.

\section{Background}

\subsection{ZDDPs}

Zinc dialkyldithiophosphates (ZDDPs) have been the principal antiwear additives in crankcase engine oils for the last eighty years [1]. They are extremely versatile and cost-effective additives, exhibiting antioxidant, corrosion inhibitor and antiscuffing performance in addition to their ability to greatly reduce wear rate. In the last three decades, however, a number of disadvantages of ZDDPs as engine oil additives have emerged. These include a deleterious impact on exhaust aftertreatment systems, relatively high friction in boundary and mixed lubrication conditions, potentially leading to a reduction in engine fuel economy, and suppression of running-in, leading to micropitting in thin film lubrication conditions. 
In the 1980s, following the widespread introduction of exhaust aftertreatment systems in road vehicles, it was found that these systems' useful life was limited by components originating from the fuel and lubricant, in particular sulphated ash, phosphorus and sulphur (SAPS) [2]. Refractory sulphated ash particles such as zinc and calcium sulphates accumulated in filters and the narrow channels of catalyst monoliths, phosphorus oxides formed coatings on catalyst surfaces, while sulphur poisoned the catalysts themselves [3]. In response to this, a series of engine oil specifications were introduced between 1994 and 2005 that progressively reduced the permitted maximum level of SAPS precursors in engine oils [1].

Since ZDDP contains zinc, phosphorus and sulphur and can thus produce all three of the components of SAPS it appeared likely by the 2000s that ZDDPs would shortly have to be partially replaced in engine oils by other antiwear additives. However, in subsequent engine oil specifications an alternative solution was found in which the permissible $\mathrm{P}$ content was held level at $0.08 \%$ wt, but a phosphorus volatility limit was introduced that required at least $79 \%$ of the initial phosphorus content in an engine oil to still be in the oil at the end of a prolonged engine test [4]. This has taken some pressure off the immediate need to replace ZDDPs in engine oils but there remains the possibility that more stringent compositional constraints may be introduced in future.

While the need to protect exhaust aftertreatment systems continues to be the main motivation for seeking replacements for ZDDPs as engine oil antiwear additives, other reasons have also emerged. In the 1970s it was noted that ZDDPs contribute to reduced engine fuel economy [5] and it was found that this resulted primarily from an increase in friction in mixed lubrication conditions, as present in parts of the piston ring/liner sliding and the cam-follower rolling-sliding contact cycles [6]. It is now recognised that this increase in mixed friction originates primarily from an increase in effective surface roughness of the surfaces due to the pad structure of ZDDP tribofilms [7].

In recent years there has been an increasing problem of micropitting wear [8]. This is a form of fatigue wear in which the cyclic stresses that result when asperities on opposing surfaces coincide drive the growth of tiny, surfaceoriginating cracks, with subsequent loss of the undermined material as micron-scale wear particles. These asperity stresses occur in high pressure contacts when surfaces are separated only by very thin lubricant films and are thus becoming more prevalent as lubricant viscosities are reduced in the quest for improved fuel economy. Although micropitting is primarily a mechanically driven process it has been found to be accelerated by ZDDPs [9-11]. This is because ZDDPs inhibit running-in, by forming tribofilms so rapidly that asperities present on the surfaces from manufacture do not have time to be smoothed or rounded. The consequent survival of relatively sharp asperities means that high asperity stresses persist for the life of the component, promoting micropitting wear.

All of above have led to strong interest in finding additives able to provide antiwear and/or extreme pressure behaviour comparable to those of ZDDPs but that avoid some of the problems discussed above and can be used as alternatives or supplements to ZDDPs in engine oils. There are a wide range of possibilities, ranging from additives that omit one of the undesirable components, metal, phosphorus or sulphur, to those that contain none of these components [12]. Two possible classes of such additives are as follows: (i) those containing phosphorus but no metal or sulphur atoms and (ii) those containing both phosphorus and sulphur, but no metal atoms. In both cases the absence of metallic species means that the additives are termed "ashless".

\subsection{Ashless P-Based Additives}

Ashless antiwear additives based only on phosphorus were first introduced in aviation, crankcase and gear lubricants in the 1940s [13,14] and they are currently used in many applications where antiwear performance is required but contact conditions are not so severe as to require a significant extreme pressure response. These include aviation turbine oils, automatic transmission fluids and some hydraulic oils [15]. Reviews of the history and mechanisms of P-containing antiwear have been provided by Khorramian et al. [16], Papay [17], Spikes [12], Johnson and Hils [18] and Guan et al. [19].

The main P-containing chemistries proposed as antiwear additives are shown in Fig. 1. The R- substituent groups are
Fig. 1 Molecular structures of main classes of organophosphorus compounds suggested as antiwear additives [12]

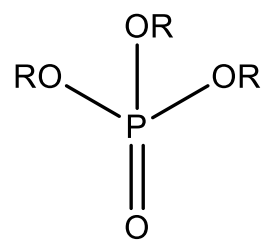

(a) Phosphate<smiles>[R]OP([R])[R]</smiles>

(b) Phosphite<smiles>[R][PH]([R])([R])=O</smiles>

(c) Phosphonate<smiles>[R][R]([R])([R])=O</smiles>

(d) Phosphinate 
usually alkyl, aryl, $\mathrm{H}$ or functionalised alkyl, and the -OR groups may be substituted by alkyl aminic or amidic groups.

The first phosphorus-based antiwear additives were the trialkyl and triaryl-phosphates, and tricresyl phosphate (TCP) was already in use as an antiwear additive in aircraft engine oils in the late 1930s [14, 20]. It is still employed in this role today, thus demonstrating even greater longevity than ZDDP. Early research suggested that it reacted in rubbing contact condition to form iron phosphide which led to polishing of the rubbed surfaces [20], but later research suggested that the main component in the protective film formed was iron (III) phosphate [21-23].

Guan et al. have recently reviewed the various suggested mechanisms of TCP as an antiwear additive [19]. They conclude that a probable mechanism involves initial $\mathrm{P}=\mathrm{O}$ bonding of intact TCP to the surface followed by nucleophilic attack of residual $\mathrm{H}_{2} \mathrm{O}$ or surface $\mathrm{O}^{2-}$ on the $\mathrm{P}$ atom, resulting ultimately in the formation of a metal phosphate or polyphosphate. There have been few studies of the thickness of tribofilms formed by the trialkyl and triaryl-phosphates but Gauthier et al. estimated TCP tribofilm thickness using a film removal method and suggested a thickness of ca $100 \mathrm{~nm}$ [24].

Dialkyl phosphates and phosphites, in which one of the -OR groups in Fig. 1a, b is -OH, are acidic and have generally been found to be more reactive than the trialkyl- and triaryl-phosphates. Forbes et al. studied the load-carrying and antiwear properties of dialkyl phosphates and their amine salts and showed that short-chain esters offered superior load-carrying properties, while long-chain esters had better wear-reducing properties $[25,26]$. Sakurai et al. observed a correlation between the wear-reducing properties of a range of lauryl-phosphates and phosphites and their reactivity towards the surface and found that dialkyl compounds performed better than their neutral trialkyl counterparts [27]. Analysis of their tribofilms by X-ray spectroscopy revealed the presence of basic iron phosphate, $\mathrm{FeFe}_{4}\left(\mathrm{PO}_{4}\right)_{3}(\mathrm{OH})_{5}$, combined with small quantities of other forms of iron phosphate, $\mathrm{Fe}_{3}\left(\mathrm{PO}_{4}\right)_{2}$ and $\mathrm{Fe}\left(\mathrm{PO}_{4}\right)$, and traces of iron phosphide on the surface.

Dialkyl and diaryl-phosphites are tautomeric with phosphonates, as shown in Fig. 2, and are used in the formulation of metalworking fluids and some transmission oils. They appear to behave rather differently from the other classes of phosphorus ester, showing significant extreme pressure properties [28, 29], good wear-reducing properties [30, 31] and an ability to form relatively thick films, i.e. $60-100 \mathrm{~nm}$, tribofilms on rubbing surfaces [27, 32].

Forbes et al. studied the four-ball wear and extreme pressure properties of dialkyl and diaryl-phosphonates. They found that short-chain phosphonates reacted rapidly with the asperities in contact to form phosphoric acid salts (i.e. extreme pressure capability), while long-chain phosphonates

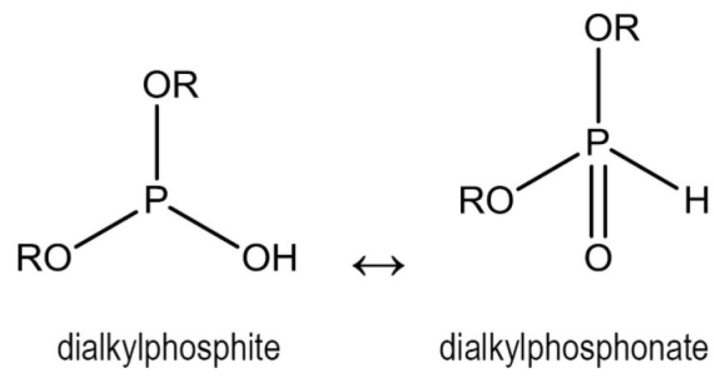

Fig. 2 Tautomerism between the dialky- and diaryl-phosphites and phosphonates

reacted more slowly to form wear-reducing organophosphate films [33].

Further work using optical interferometry to study the film-forming properties of a range of dialkyl and diarylphosphonates showed that these compounds rapidly form ca. 100-nm-thick tribofilms at $75{ }^{\circ} \mathrm{C}$ in mixed rolling/sliding conditions [34-36]. Analysis of the reaction films using infrared and Mossbauer spectroscopies suggested the formation of an iron alkylphosphate polymer film on the surface for hexyl and octyl phosphonates, with the iron present as low-spin iron (III) [35].

From the above it appears that the trialky- and triarylphosphates form an iron polyphosphate or iron phosphate film on rubbed metal surfaces. No film was found to form from TCP solution on $\mathrm{SiC}$ and $\mathrm{Si}_{3} \mathrm{~N}_{4}$, confirming the role of the metal in forming a phosphate-based salt [37]. Acidic phosphates or alkylamine phosphates react faster than the trialkyl/triaryl-phosphates and phosphites but appear to produce a similar tribofilm. The diaryl- and dialkylphosphonates clearly behave very differently, rapidly forming thick tribofilms that consist, not primarily of inorganic phosphates but of organophosphate complexes. The reason for this difference is not yet clear but suggests that these additives may extract the ferric ions needed to stabilise a tribofilm much more easily and rapidly than other organophosphorus additives. It is not yet known whether this reflects a greater corrosivity of the phosphonates or a greater passivation by the phosphates.

\subsection{Ashless P/S-Based Additives}

A key practical feature of ashless additives containing both phosphorus and sulphur is that like ZDDPs they combine antiwear behaviour due to their phosphorus with an extreme pressure response due to their sulphur content. These make them potential replacements for ZDDP in engine oils without the need for supplementary extreme pressure additives to prevent scuffing of sliding cam-follower systems. Their sulphur content also contributes to their antioxidant properties, especially in terms of peroxide decomposition. 
Ashless lubricant additives containing both sulphur and phosphorus were first developed in the 1940s to provide the benefits of both antiwear and extreme pressure protection in high-sliding gears such as hypoids and spiral bevels [38]. They were made by reaction of $\mathrm{P}_{2} \mathrm{~S}_{5}$ with olefins, alcohols and fatty esters to form reaction products having both phosphorus and sulphur-based functional groups, and are still used in gearbox lubricants today. However their poorly defined structure has meant that very little systematic research has been carried out on these additives beyond measurement of their wear and scuffing performance. Compared to ZDDP and ashless P-additives, research on welldefined organothiophosphorus additives started relatively recently. A review of P-S-containing antiwear has been given by Spikes [12].

Many ashless thiophosphorus lubricant additives have been proposed but there are two main types. One is based on triaryl and trialkyl thiophosphates in which one or more of the oxygen atoms shown in Fig. 1a, b is replaced by a sulphur atom. The second retains the core dialkydithiophosphate grouping found in ZDDP, but in the absence of a $\mathrm{Zn}$ atom, one of its sulphur atom is bonded to a functionalised alkyl group.

Schumacher et al. studied the influence of alkyl groups and number of $\mathrm{S}$ and $\mathrm{O}$ atoms on the wear-reducing properties of a range of phosphate esters derivatives. The authors suggested that the key to antiwear efficiency was the thermal stability of the P-S-containing compounds investigated, i.e. additives should be thermally stable to avoid decomposition in the bulk, but reactive within the contact $[39,40]$

Taylor et al. used MTM-SLIM to investigate the filmforming properties of tri-n-butyl thiophosphate in which the $\mathrm{P}=\mathrm{O}$ of the phosphate ester is replaced by $\mathrm{P}=\mathrm{S}$. They found that this additive slowly reacted to form a thick protective film on the surface, i.e. $\approx 70 \mathrm{~nm}$ thick after $3 \mathrm{~h}$ of rubbing at $100{ }^{\circ} \mathrm{C}$ [41]. The tribofilm formed by the same thiophosphate was further investigated by Rossi et al. using XPS and FTIR analysis. The authors reported the formation of iron polyphosphate and iron sulphate in the contact [42]

Mangolini et al. studied the tribofilms formed by triphenyl thiophosphate using an in-situ ATF method at $150{ }^{\circ} \mathrm{C}$ [43]. Similar to Rossi et al. they detected short-chain and long-chain polyphosphates, and iron sulphates, as well as carbonates and carboxylates, the latter probably produced by base oil oxidation. Friction was higher than for the base oil alone.

Borshchevskii et al. studied the antiwear properties of a range of functionalised dithiophosphates. They found that compounds prepared using functionalised alkenes, e.g. methacrylic acid, gave better wear-reducing properties than those prepared using non-functionalised alkenes (i.e. simple alkenes $\mathrm{C}_{\mathrm{n}} \mathrm{H}_{2 \mathrm{n}}$ ). The authors attributed this to the higher nucleophile strength of functionalised alkenes [44]. More recently, Sharma et al. ascribed this to the stronger adsorptive power of functionalised dithiophosphate derivatives on steel surfaces [45].

Najman et al. used XANES to investigate the nature of the protective films formed by two functionalised dialkyldithiophosphates: a carboxylic acid-substituted, i.e. $-\mathrm{COOH}$, and an ester-substituted, i.e. -COOR as well as one trialkyl-aryl thiophosphate [46]. All three additives gradually reacted to form a short-chain $\mathrm{Fe}(\mathrm{II})$ polyphosphate film after $5 \mathrm{~min}$ of rubbing. Further analysis revealed the presence of $\mathrm{FeSO}_{4}$ on the surface after extended periods of rubbing, i.e. $6 \mathrm{~h}$. It was also reported that the carboxylic acid-substituted dithiophosphate reacted more rapidly than the other additives to form a tribofilm, but gave higher initial wear. This was attributed to the mildly corrosive nature of the acidic by-products generated by tribochemical decomposition, which in turn contributed to the removal of Fe cations from the substrate that then enabled formation of a polyphosphate film.

More recently, Kim et al. studied the wear-reducing properties of a range of functionalised alkyl and aryl dithiophosphate derivatives under extreme pressure conditions [47]. Contrary to Najman et al., they reported that the acid-substituted dialkyldithiophosphate, i.e. - $\mathrm{COOH}$, offered better antiwear properties than its neutral counterpart. This additive also showed superior wear-reducing properties to aryl dithiophosphates. Subsequent analysis of the wear debris by transmission electron microscopy (TEM) revealed the presence of nanocrystalline particles of $\mathrm{Fe}_{3} \mathrm{O}_{4}$ embedded within an amorphous film [47].

\section{Test materials}

A single API group III base oil, Yubase $4(19.2 \mathrm{cSt}, 15.7 \mathrm{cP}$ at $40{ }^{\circ} \mathrm{C} ; 4.24 \mathrm{cSt}, 3.31 \mathrm{cP}$ at $100{ }^{\circ} \mathrm{C} ; \mathrm{VI}=128$ ) was used throughout the current study. Six ashless P-additives, eight ashless P/S additives and one ZDDP were studied, as listed in Tables 1 and 2, which also show their molecular structures where known. Some were model chemicals and some commercial antiwear additives. All were used at a concentration corresponding to $800 \mathrm{ppm}$ phosphorus. Of interest in this study was the role of metal cations in helping formation of an antiwear films and Table 3 shows two metal-containing oil soluble additives that were used to explore the importance of such ions in tribofilm formation. These were used at various concentrations [48] but the results reported in this paper are at $1 \% \mathrm{wt}$. 
Table 1 Ashless P-additives studied

Abbreviation Description

Tri-iP-P(V)

Triisopropyl phosphate (Sigma-Aldrich)<smiles>CC(C)OP(=O)(OC(C)C)OC(C)C</smiles>

Tri-iP-P(III)

Triisopropyl phosphate (Sigma-Aldrich)<smiles>CC(C)OP(OC(C)C)OC(C)C</smiles>

$\mathrm{BEH}-\mathrm{P}(\mathrm{V})$

Bis(2-ethylhexyl) phosphate (Sigma-Aldrich)<smiles>CCCCC(CC)COP(=O)(O)OCC(CC)CCCC</smiles>

BEH-P(III)

Bis(2-ethylhexyl) phosphite (Sigma-Aldrich)<smiles>CCCCC(CC)COP(O)OCC(CC)CCCC</smiles>

TAP

AP
Triaryl-phosphate blended with a small proportion of dialkylphosphate ester (commercial)

Amine phosphate (commercial)

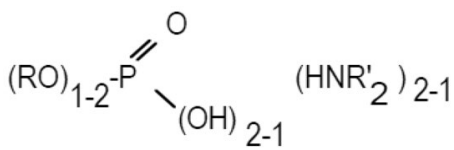


Table 2 ZDDP and ashless PS-based additives studied

\section{Test Methods}

\subsection{MTM-SLIM; Friction and Tribofilm Thickness}

A mini traction machine with spacer layer imaging mapping (MTM-SLIM) was used to explore the friction and filmforming properties of the test lubricants under mixed rolling/ sliding conditions. This is shown schematically in Fig. 3. A rolling/sliding contact is generated between a $19 \mathrm{~mm}$ diameter steel ball and the flat surface of a steel disc immersed in the test lubricant at a controlled temperature. The ball drive-shaft is angled to minimise spin, while frictional force is measured by a load cell attached to the ball shaft holder. 
Table 3 Metallic supplements studied

\begin{tabular}{ll}
\hline Abbreviation & Description \\
\hline $\mathrm{CaSu}$ & Neutral \\
& calcium \\
& sulphonate \\
& (commer- \\
& cial) \\
& Titanium (IV) \\
TiPO & isopropoxide \\
& (Sigma- \\
& Aldrich) \\
\hline
\end{tabular}

The MTM test conditions used in the current study are listed in Table 4. All tests were carried out at $100{ }^{\circ} \mathrm{C}$ and lasted $2 \mathrm{~h}$ and during this time ball and disc were rubbed together at an entrainment speed of $0.1 \mathrm{~m} / \mathrm{s}$. At this low entrainment speed, the theoretical EHD film thickness was only $9 \mathrm{~nm}$, so the contact operated in mixed lubrication conditions from the outset. Periodically throughout a test the ball and disc motion were halted and a tribofilm thickness measurement was taken using the spacer layer imaging method (SLIM). For this the ball is uploaded against a coated glass disc and white light shone into the resulting contact, where some is reflected by a semi-reflective coating on the underside of the glass while the remainder passes through a silica spacer layer and any antiwear film on the ball before being reflected back from the steel substrate. The two beams undergo optical interference depending on their optical path difference and thus on the antiwear film thickness. The result is an interference image as shown in Fig. 4, which is captured as a RGB pixel map by a high resolution camera. A calibration chart of RGB colour versus optical path difference obtained using ultrathin film interferometry is then used to convert this RGB pixel map to a tribofilm thickness map. Mean film thicknesses were then determined from $50 \mu \mathrm{m}$ diameter circular region in the centre of the contact image. At the start and end of the two hour test a Stribeck friction curve was obtained, where friction

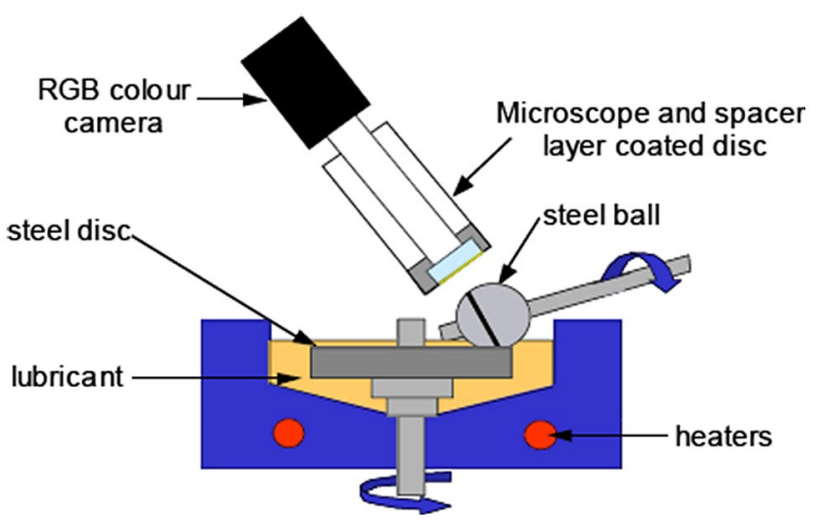

Fig. 3 Schematic diagram of MTM-SLIM
Table 4 MTM test conditions for film thickness and friction tests

\begin{tabular}{ll}
\hline Temperature & $100{ }^{\circ} \mathrm{C}$ \\
\hline Load & $30 \mathrm{~N}$ \\
Maximum Hertz contact pressure & $0.95 \mathrm{GPa}$ \\
Slow speed rolling/sliding & \\
Entrainment speed & $0.1 \mathrm{~m} / \mathrm{s}$ \\
Slide-roll ratio (SRR) & $50 \%$ \\
Duration & $120 \mathrm{~min}$ \\
Theoretical EHD film thickness $\left(h_{0}\right)$ & $9 \mathrm{~nm}$ \\
Lambda ratio $(\lambda)$ & 0.6 \\
Stribeck curves & \\
Entrainment speed & 3.5 to $0.01 \mathrm{~m} / \mathrm{s}$ \\
Slide-roll ratio $(\mathrm{SRR})$ & $50 \%$ \\
Specimens & \\
Balls & AISI 52,100 \\
& steel; \\
& Hardness: \\
& $850 \pm 15 \mathrm{Hv}$ \\
& Root mean \\
square \\
Discs & roughness \\
& $5.5 \pm 1 \mathrm{~nm}$ \\
& AISI 52,100 \\
& steel; \\
& Hardness: \\
& $835 \pm 15 \mathrm{Hv}$ \\
& Root mean \\
square & roughness \\
& $11 \pm 2 \mathrm{~nm}$ \\
\hline
\end{tabular}

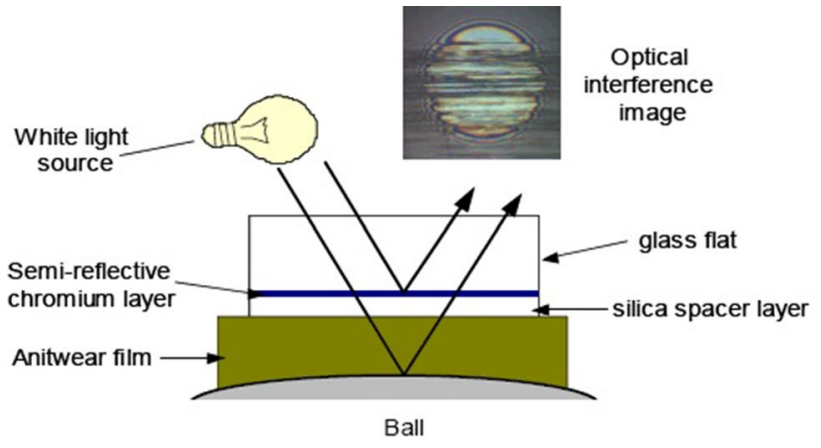

Fig. 4 Principle of spacer layer interferometry method

was measured at a series of entrainment speeds from 3.5 to $0.01 \mathrm{~m} / \mathrm{s}$, maintaining a constant slide-roll ratio of $50 \%$.

In this study a refractive index of 1.60 was employed for all SLIM measurements in order to convert the measured optical film thickness to actual film thickness. This value is based on the optical properties of zinc phosphate glasses [49]. It is not necessarily valid for the tribofilms formed from non-zinc containing phosphates but fortunately the refractive 
indices of most transparent materials lie in a relatively narrow range, from about 1.4 to about 1.7 , so an assumption of 1.6 implies that any resulting error will not exceed about $15 \%$.

\subsection{Reciprocating MTM; Wear Measurement}

To assess the wear performance of the additives, the MTM was used in reciprocating mode. In this the ball rotates continuously but the disc reciprocates. In terms of mild wear measurement this has two advantages over unidirectional rolling-sliding or pure sliding. Firstly, by using reciprocating motion the wear on the disc is localised over a relatively small region, thus increasing the wear depth, as compared to unidirectional rolling-sliding motion in which wear is distributed around the whole MTM disc circumference. However, unlike pure sliding (e.g. pin-on-disc or HFRR) where one surface is continuously in contact and thus experiences a very high level of local wear, in the reciprocating MTM, both surfaces move with respect to the contact. This means that the local amount of wear is enough to ensure measurable wear but not so much as to significantly change contact geometry and thus contact pressure.

In this study, the disc stroke length was $4 \mathrm{~mm}$ and the stroke frequency $10 \mathrm{~Hz}$. This gave an average disc surface speed with respect to the contact of $80 \mathrm{~mm} / \mathrm{s}$. The ball speed was $20 \mathrm{~mm} / \mathrm{s}$ so the mean entrainment speed was $0.05 \mathrm{~m} / \mathrm{s}$. The other test conditions were the same as for MTM friction/film thickness tests, i.e. AISI 52,100 steel ball and disc, $\operatorname{load}=30 \mathrm{~N}$ and test temperature $=100{ }^{\circ} \mathrm{C}$. At the end of a test, ball and disc were removed from the test rig, rinsed with hexane and wrapped in lens cleaning paper for further study.

Figure 5 shows a typical wear scar on the MTM disc. A Veeco WYKO NT9100 scanning white light interferometer (SWLI) was used in vertical scanning interferometry (VSI) mode to quantify this wear. Previous work by the authors has found that the thick tribofilms formed by ZDDPs produce an optical artefact when using SWLI that obviates wear measurement because the incident light undergoes multiple reflection within the transparent tribofilm. To study the topography of the tribofilm itself this can be overcome by coating the film with a thin layer of reflective gold. However, for wear measurement the tribofilm must be removed prior to SWLI use. With ZDDP it was found that the film of primarily zinc phosphate could be removed by brief application of a solution of ethylenediaminetetraacetic acid (EDTA) [50].

However, in the current study it was found that the tribofilms formed by ashless additives could not be removed by EDTA alone [48]. This may be because the principle cation present is $\mathrm{Fe}$ (III) rather than $\mathrm{Zn}$ (II). It was, however, found that the tribofilms could be removed by a combination of oxalic acid and EDTA solutions. Oxalic acid, a dibasic acid and reducing agent, is another well-known chelating agent that forms stable complexes with metal cations, e.g. Fe and it is also well-known for its ability to dissolve iron oxides [51]. For non-ZDDP-derived tribofilms, a droplet of $0.05 \mathrm{M}$ oxalic acid solution in distilled water was placed on the rubbed track for $20 \mathrm{~s}$. The solution was then removed by touching the droplet with a tissue. It was found that exposing the surface for longer periods of time caused damage to the surface in the form of an increased high frequency roughness after EDTA treatment. Then a droplet of 0.05 M EDTA solution in distilled water was placed on part of the rubbed track for one minute. This solution was then also removed by touching the droplet with a tissue.

After the tribofilms were removed by EDTA or oxalic acid/EDTA, a topography image was taken using the SWLI and wear depth measurements determined at both ends, where disc speed is a minimum, and in the middle of the wear track where disc speed reaches a maximum. From these, Archard wear coefficients were determined from;

$k_{1}=\frac{V}{W L}$
Fig. 5 Wear scar on the disc after reciprocating test

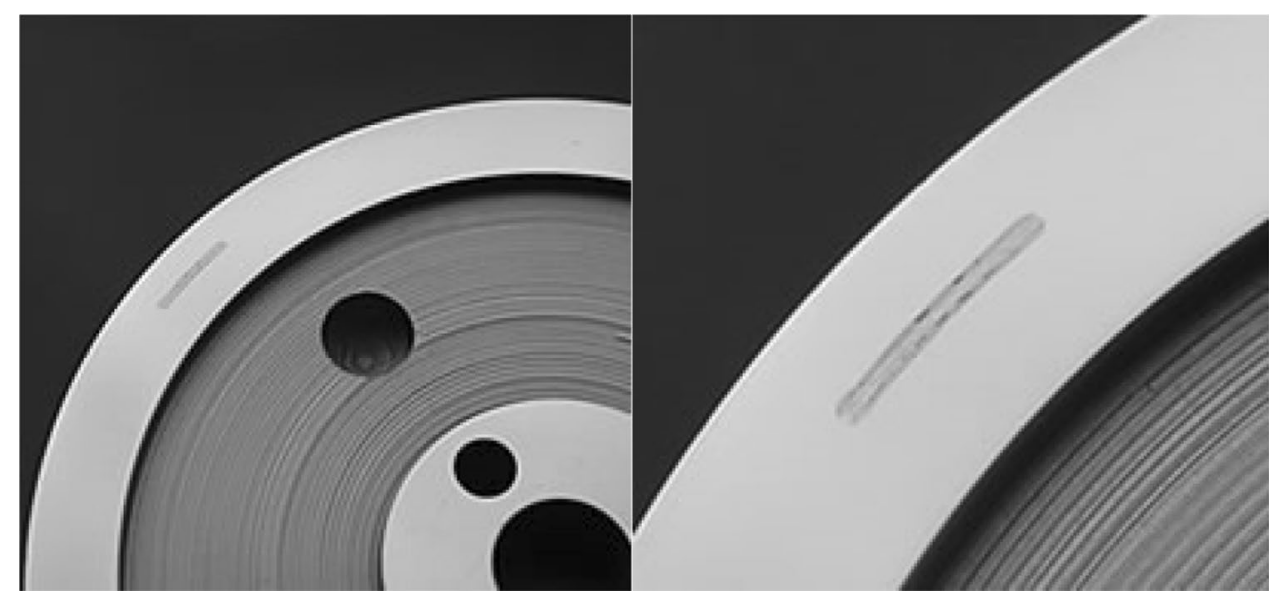


where $V$ is the local wear volume, $W$ the applied load and $L$ the sliding distance. As described in [48] this can be converted to;

$k_{1}=\frac{d}{4 a p_{m n} N^{u_{b}} / u_{d}}$

where $d$ is the wear depth, $p_{m n}$ is the mean pressure, $a$ the disc track half width, $N$ the number of cycles, and $u_{b}$ and $u_{d}$ respectively the speeds of the ball and disc with respect to the contact.

Three different tests, lasting respectively $4 \mathrm{~h}, 8 \mathrm{~h}$ and $16 \mathrm{~h}$, were carried out in order to highlight any variations that might occur over time, for example due to running-in or the build-up of corrosive products and these sets of three tests were repeated twice.

\subsection{Tribofilm Characterisation}

Atomic force microscopy (AFM) was used to characterise the morphology of antiwear additive-derived tribofilms. Two AFM instruments were employed in this study: a Veeco diCaliber AFM (Imperial College London) and a
Veeco Dimension 3100 SPM (University of Nottingham), both using a v-shaped silicon nitride $\left(\mathrm{Si}_{3} \mathrm{~N}_{4}\right)$ cantilever with a nominal $20 \mathrm{~nm}$ radius pyramidal, $\mathrm{Si}_{3} \mathrm{~N}_{4}$ tip, in contact mode. An area of $100 \mu \mathrm{m} \times 100 \mu \mathrm{m}$ in the centre and at the edge of the wear track was scanned and the topography of the tribofilm evaluated.

In this study, XANES was employed to investigate the chemical composition of antiwear additive-derived tribofilms. XANES spectra for the species of interest were obtained at the $1.7 \mathrm{GeV}$ storage ring at Helmholtz-Zentrum Berlin für Materialien und Energie $\mathrm{GmbH}$ (HZB) and at the 2.9 GeV storage ring at Canadian Light Source (CLS, Saskatoon, Canada). To explore the chemical nature and oxidation state of elements at the outermost surface and bulk, spectra were recorded using TEY and FY modes of detection. At least three scans were digitally combined and a background was removed after normalisation. Before loading the discs into the ultrahigh vacuum (UHV) chamber for testing, these were cleaned by immersion in hexane in an ultrasonic bath for $10 \mathrm{~min}$. Table 5 summarises XANES test conditions and Table 6 lists the model reference compounds employed in this study to aid interpretation of the tribofilm spectra. For the latter, powder and glass-like model compounds were

Table 5 XANES test conditions

\begin{tabular}{|c|c|c|c|}
\hline $\begin{array}{l}\text { Synchrotron radiation } \\
\text { facility }\end{array}$ & $1.7 \mathrm{GeV}$ storage ring at $\mathrm{HZB}$ & $2.9 \mathrm{GeV}$ storage ring at CLS & \\
\hline Beamline & $\begin{array}{l}\text { Double crystal monochromator: } \\
\text { Si(111); KMC-1 }\end{array}$ & $\begin{array}{l}\text { Variable line spacing plane grating mono- } \\
\text { chromator (VLS PGM); 11ID-2 }\end{array}$ & $\begin{array}{l}\text { Soft X-ray microcharacterszation } \\
\text { beamline; (SXRMB); 06B1-1; } \\
\text { XAFS }\end{array}$ \\
\hline Energy range & $2000-12,000 \mathrm{eV}$ & $5.5-250 \mathrm{eV}$ & $1700-10,000 \mathrm{eV}$ \\
\hline Spot size & $500 \mu \mathrm{m} \times 500 \mu \mathrm{m}$ & $500 \mu \mathrm{m} \times 500 \mu \mathrm{m}$ & $300 \mu \mathrm{m} \times 300 \mu \mathrm{m}$ \\
\hline
\end{tabular}

Table 6 Model compounds used for XANES analysis

\begin{tabular}{lll}
\hline Model compound name & Description & Supplier \\
\hline $\mathrm{Fe}\left(\mathrm{PO}_{3}\right)_{3}$ & Iron metaphosphate glass & Maura Crobu [53, 54] \\
$\mathrm{FePO}_{4}$ & Iron (III) phosphate & Acros Organics \\
$\mathrm{Fe}_{4}\left(\mathrm{P}_{2} \mathrm{O}_{7}\right)_{3}$ & Iron (III) pyrophosphate & Sigma-Aldrich \\
$\mathrm{Fe}_{10} \mathrm{P}_{18} \mathrm{O}_{55}$ & Iron polyphosphate glass (Fe/P: 0.5) & Maura Crobu [53, 54] \\
$\mathrm{Zn}_{\mathrm{P}}$ & Zinc ultraphosphate glass (Zn/P: 1/3) & Maura Crobu [53, 54] \\
$\mathrm{ZnP}_{2} \mathrm{O}_{6}$ & Zinc metaphosphate glass & Maura Crobu [53, 54] \\
$\mathrm{Zn}_{2} \mathrm{P}_{2} \mathrm{O}_{7}$ & Zinc pyrophosphate glass & Maura Crobu [53, 54] \\
$\mathrm{Zn}_{4} \mathrm{P}_{6} \mathrm{O}_{19}$ & Zinc polyphosphate glass & Maura Crobu [53, 54] \\
$\mathrm{Zn}_{3}\left(\mathrm{PO}_{4}\right)_{2}$ & Zinc phosphate & Sigma-Aldrich \\
$\mathrm{Zn}_{3} \mathrm{P}_{2}$ & Zinc phosphide & Sigma-Aldrich \\
$\mathrm{Amine} \mathrm{phosphate}$ & - & - \\
$\mathrm{ZnS}_{\mathrm{ZnSO}}$ & Zinc sulphide & Sigma-Aldrich \\
$\mathrm{FeS}$ & Zinc sulphate & Sigma-Aldrich \\
$\mathrm{FeS}_{2}$ & Iron (II) sulphide & Sigma-Aldrich \\
$\mathrm{Na}_{2} \mathrm{SO}_{3}$ & Iron disulphide (pyrite) & Alfa Aesar \\
$\mathrm{FeSO}_{4}$ & Sodium sulphite & Sigma-Aldrich \\
\hline & Iron (II) sulphate & Sigma-Aldrich \\
\hline
\end{tabular}


pressed onto a conducting carbon tape mounted on the sample holder and loaded into the UHV chamber for analysis. Due to the volatility of some liquid model compounds, a thin liquid film was prepared by spreading a small drop of liquid on the carbon tape which was transferred to the sample holder and subsequently analysed [52].

Time-of-flight secondary ion mass spectrometry (ToF-SIMS) was used to generate chemical surface maps of antiwear additive-derived tribofilms. ToF-SIMS experiments were carried out on MTM discs using an ION-TOF IV. Surface imaging was obtained using a $\mathrm{Bi}^{+}$liquid metal ion gun (LMIG) at a maximum sampling depth of $2 \mathrm{~nm}$. An area of $500 \mu \mathrm{m} \times 500 \mu \mathrm{m}$ spanning rubbed/unrubbed areas or at the edge of the wear track was submitted to analysis and a chemical map for the element or molecule of interest was obtained using the instrument software. Before loading the discs into the ultrahigh vacuum (UHV) chamber for testing, these were cleaned by immersion in hexane in an ultrasonic bath for $10 \mathrm{~min}$. Table 7 lists the ToF-SIMS test conditions used in this study.

\section{MTM-SLIM Film Thickness Results}

Figure 6 shows SLIM images indicating the growth of tribofilm on MTM balls with increasing rubbing time for the base oil, the ZDDP solution and the ashless P-containing additive solutions. With the base oil alone, scuffing occurred after 5 min of rubbing and the test was terminated. Figure 7 shows mean film thicknesses from the central region of the rubbed ball track determined from the SLIM images for the P-containing additives while Fig. 8 shows the film thicknesses determined for the P/S-containing additives. SLIM images from tests using $\mathrm{P} / \mathrm{S}$ additive solutions are shown in the Appendix.

It can be seen that the primary ZDDP rapidly forms a thick solid-like film on the rubbed ball, while the P-containing compounds form thinner films, 60 to $80 \mathrm{~nm}$ for the alkyl phosphates and phosphites and extremely thin tribofilms for the triaryl-phosphate (TAP) and the amine phosphate

Table 7 ToF-SIMS conditions

\begin{tabular}{ll}
\hline Test apparatus & $\begin{array}{c}\text { ToF-SIMS IV from ION- } \\
\text { TOF GmbH of Münster, } \\
\text { Germany }\end{array}$ \\
Primary ion species & $\mathrm{Bi}_{3}^{+}(\mathrm{LMIG})$ \\
Scan size & $500 \mu \mathrm{m} \times 500 \mu \mathrm{m}$ \\
Image & $256 \times 256$ pixel raster \\
Sampling depth & $2 \mathrm{~nm}$ (maximum) \\
Spatial resolution of $100 \mathrm{~nm}$ & $>100 \mathrm{~nm}$ \\
Mass resolution & $>7000$ at m/z=29 \\
Mass analyser & Reflectron \\
\hline
\end{tabular}

mixture (AP). The P/S-based additives form thinner films than most of the P-containing additives, with PS and PNS forming negligible films. For additives that form measureable films, film growth is quite rapid over the first $20 \mathrm{~min}$ rubbing and then slows down or stabilises.

It can be seen in Fig. 6 that some of the additives that show little film growth (Tri-iP-P(V), TAP and AP) have dark

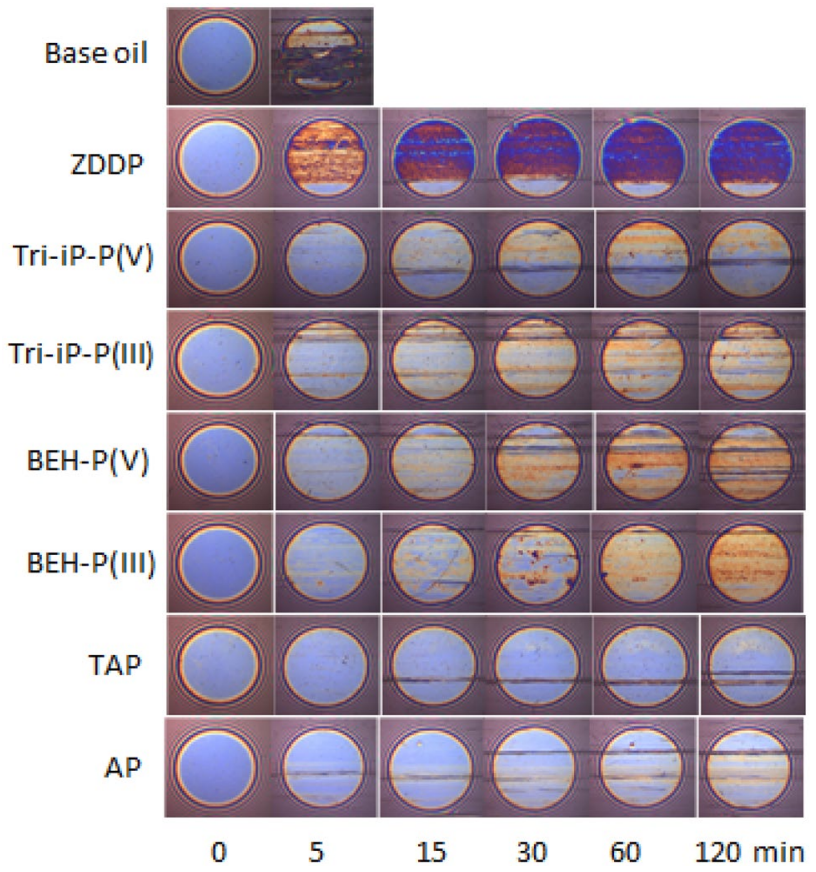

Fig. 6 SLIM images from tests of various test fluids

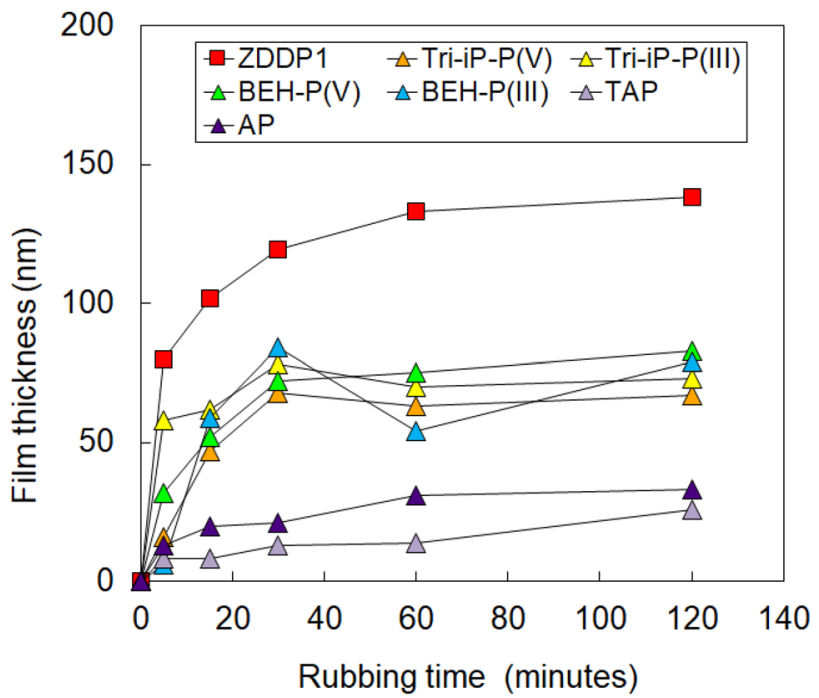

Fig. 7 Tribofilm thicknesses of P-containing additive solutions determined from SLIM images 
lines across the surface in the direction of sliding. Some of these indicate lines of thicker film and probably originate from severe contact conditions that occur when debris particles pass through the rolling-sliding contact. Similar lines were seen with ATP, BTAPPT, DATP and TPPT. They suggest that a tribofilm can form but at higher contact stresses than were normally present in these tests.

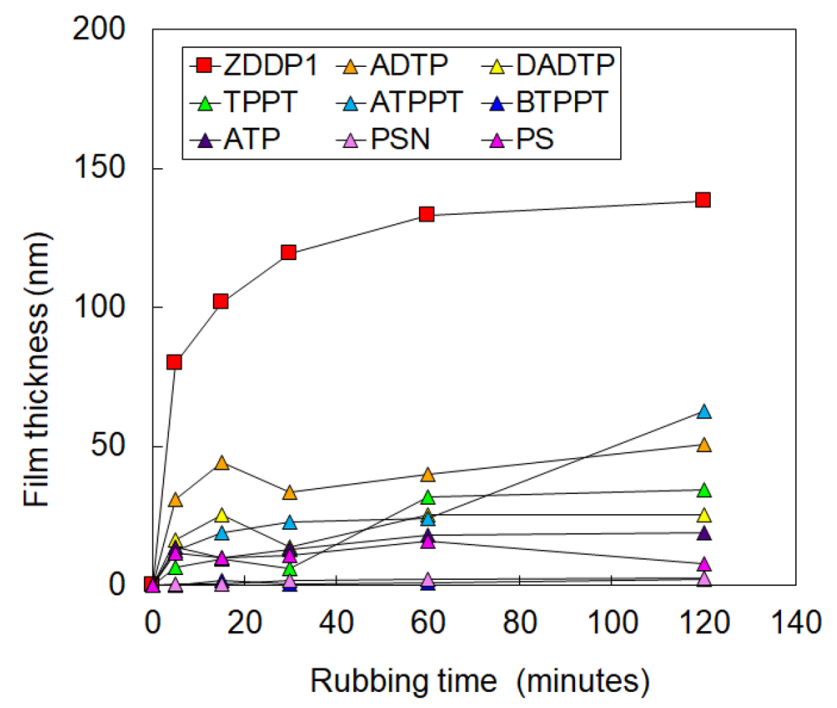

Fig. 8 Tribofilm thicknesses of P/S-containing additive solutions determined from SLIM images

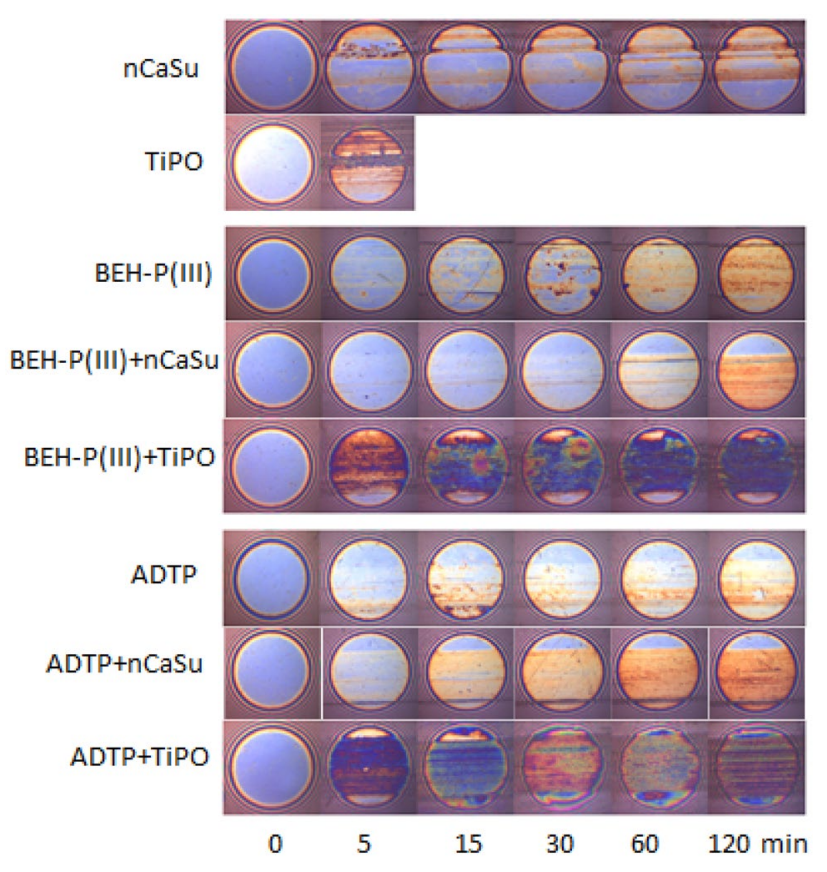

Fig. 9 Impact of metal-containing additives on ashless P- and P/S additive film growth
As suggested by other researchers, it is likely that these P-containing additives form tribofilms less readily than ZDDP because of the absence of readily available metal cations to stabilise the phosphate film. To explore this, additional tests were carried out to investigate the influence of two separate metal cations on the stabilisation of the protective film. Neutral calcium sulphonate detergent and titanium (IV) isopropoxide were individually blended at a concentration of $1 \%$ wt. with bis(2-ethylhexyl) phosphite and the ester-based dialkydithiophosphate, ADTP.

The film-forming properties of titanium (IV) isopropoxide and neutral calcium sulphonate detergent alone in base oil are illustrated in Fig. 9. With the titanium (IV) isopropoxide-only solution, scuffing occurred after 5 min of rubbing and the test was terminated. The film formed by the neutral calcium sulphonate-only solution seems to withstand rubbing, but the loss of circularity of the interference images shows that considerable wear is occurring.

Figure 9 shows that titanium (IV) isopropoxide/antiwear additive-containing blends rapidly form very thick tribofilms on the surface, i.e. within 5 min of rubbing. The effect of the neutral calcium sulphonate detergent is less dramatic, possibly because the alkyl sulphonate also adsorbs on the surfaces to hinder access by the antiwear additive. However after two hours rubbing it also promotes formation of a thick, even film.

\section{MTM Friction Results}

Figures 10 and 11 show Stribeck friction curves for the P-based additive solutions at the beginning and end of two hours MTM tests respectively. Even prior to slow speed rubbing, some effects of the additives are seen, with the amine phosphate and especially the triaryl-phosphate showing reduced boundary friction compared to ZDDP. However after two hours rubbing, there are large differences between the additives. The ZDDP and bis-ethylhexylphosphate show very similar response, with high boundary friction that extends to high entrainment speed. This extension of the boundary regime results from the formation of rough tribofilms [7]. Similar response, though to a lesser extent, is seen with the amine phosphate even though this only forms a very thin tribofilm. The two phosphites and triisopropyl phosphate do not show this extended boundary film region, implying either the absence of a tribofilm or one that is smooth rather than rough. The two phosphites give almost identical curves. The triaryl-phosphate shows remarkably low boundary friction.

Figures 12 and 13 show corresponding Stribeck curves for the P/S additives. Again there is an initial impact on boundary friction of the various additives, with the PS 


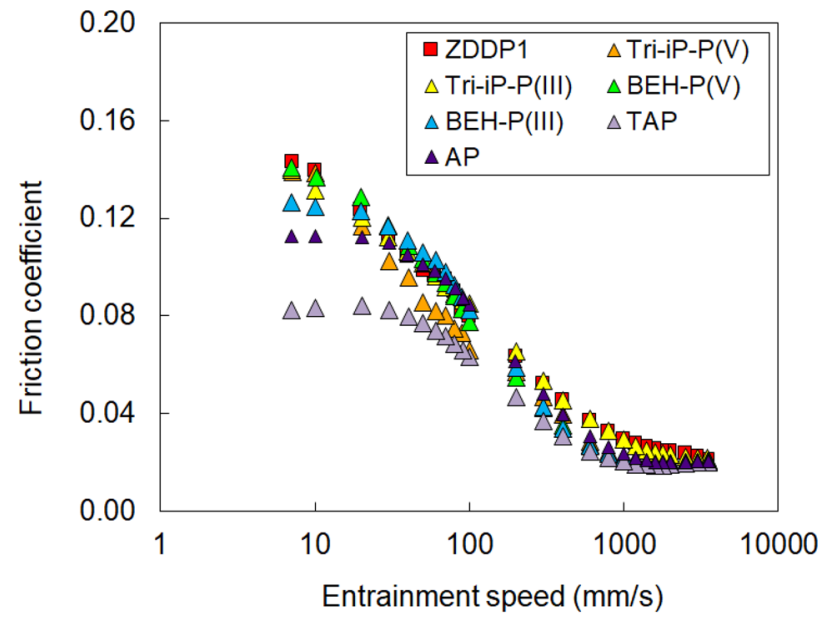

Fig. 10 Stribeck curves for ashless P-additives at the start of MTM tests

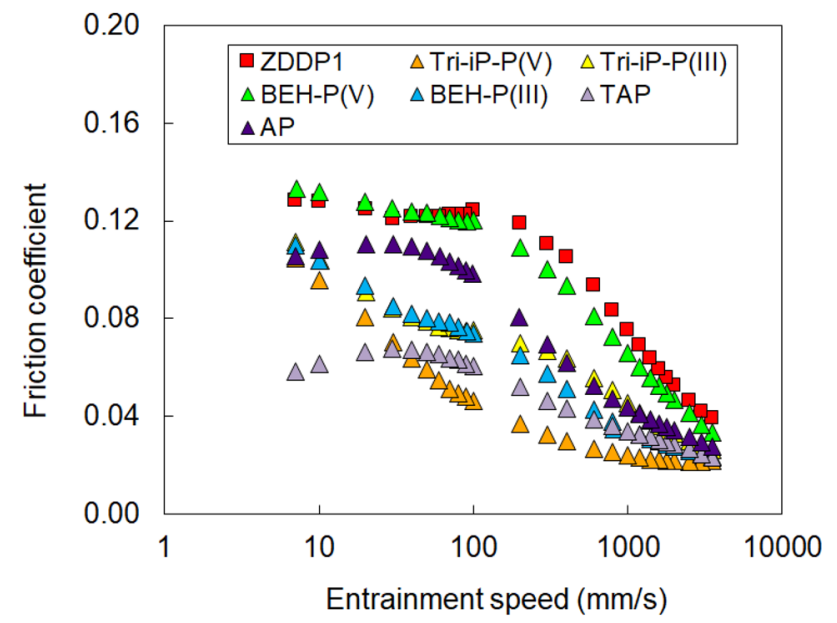

Fig. 11 Stribeck curves for ashless P-additives at the end of $2 \mathrm{~h}$ MTM tests

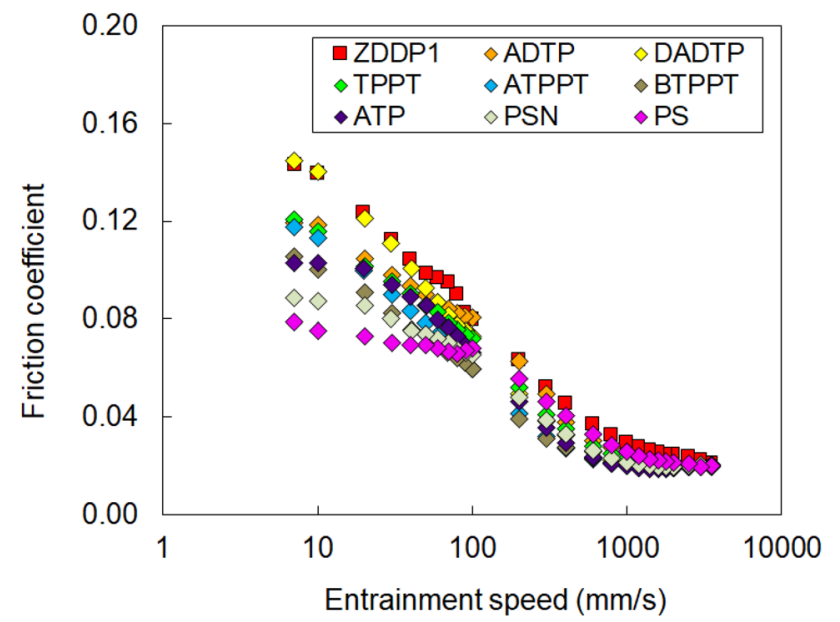

Fig. 12 Stribeck curves for ashless P/S additives at the start of MTM tests

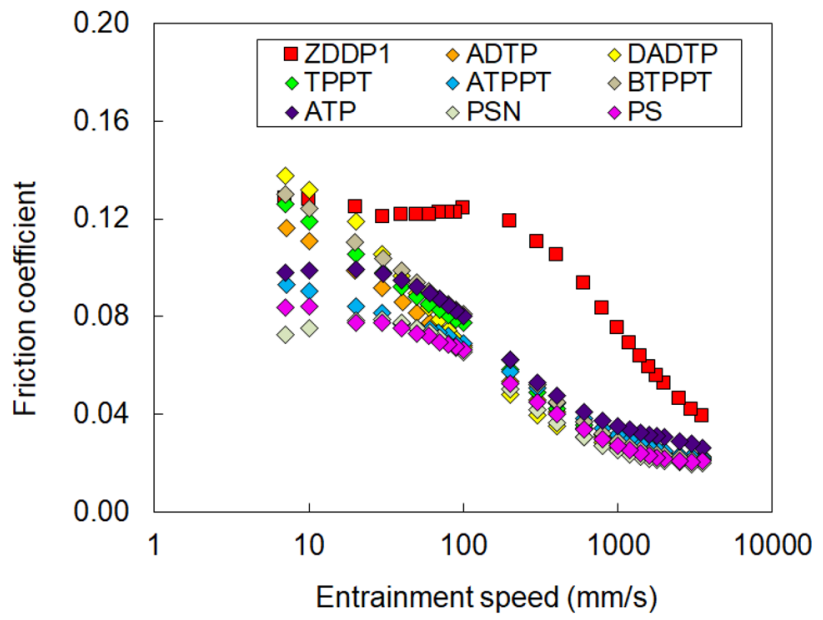

Fig. 13 Stribeck curves for ashless P/S additives at the end of $2 \mathrm{~h}$ MTM tests

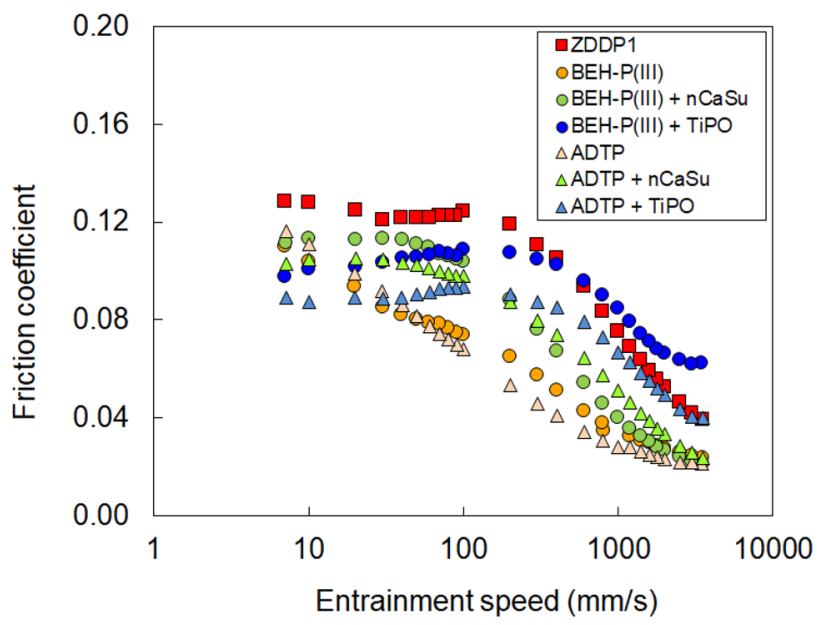

Fig. 14 Stribeck curves for combinations of ashless antiwear additives with metal ion sources

and PSN giving the lowest friction. After $2 \mathrm{~h}$ rubbing however none of the additives gives the extended boundary film speed response seen with ZDDP, indicating they do not form a rough, pad-like structure. However there are still considerable differences in boundary friction with PS, NPS, ATP and ATTP giving the lowest friction coefficients.

Figure 14 compares Stribeck curves for two of the ashless additives with those obtained when $1 \% \mathrm{wt}$. of metalcontaining additives are also present. For both additives the addition of $\mathrm{CaSu}$ or TiPO, as well as enhancing tribofilm thickness extends the boundary lubrication regime to higher entrainment speeds. However, they also reduce boundary friction. 

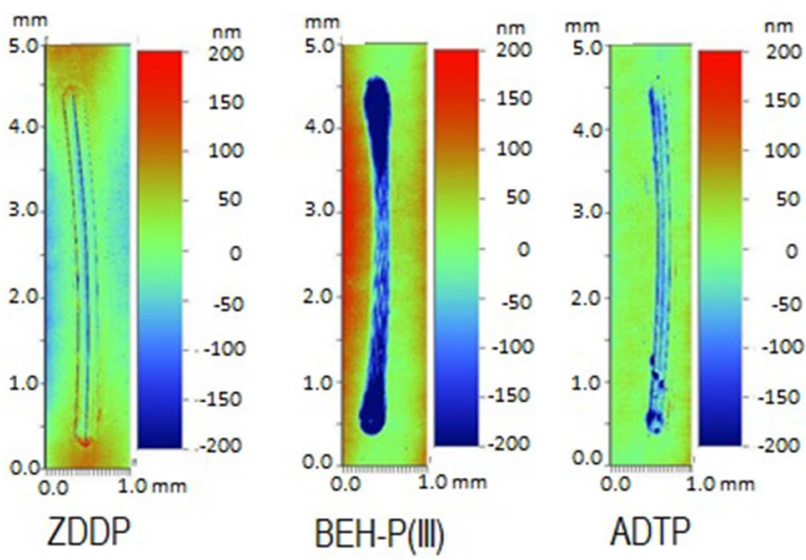

Fig. 15 Example SWLI images of wear scars on the MTM disc after removal of any tribofilm for three ashless additive solutions

\section{MTM Wear Results}

Wear tests were carried out on the ZDDP solution, five of the ashless additives and three blends of ashless additive with a metallic species. Figure 15 shows SLIM images of disc wear scars after $8 \mathrm{~h}$ reciprocating tests with three additive solutions. Before imaging, any tribofilm was removed with EDTA/oxalic acid treatment. To identify any runningin effects, separate tests of $4 \mathrm{~h}, 8 \mathrm{~h}$ and $16 \mathrm{~h}$ duration were carried out. Wear coefficients were determined both from the stroke centre and from the end, the latter being from the mean of the wear at both ends of the stroke. The mid stroke values were generally quite similar to the end stroke ones.

Figure 16 summarises the end-of-stroke wear coefficients. It should be noted that the wear coefficient axis has a logarithmic scale to encompass the very wide range of wear rates measured. Empty columns represent no measureable wear. Most sets of three tests of different duration were repeated and showed good repeatability, suggesting that the variation of wear rate with test time is significant. From Fig. 16 it can be seen that the wear rate is generally higher in a four hour test than in a 8- or 16-h tests. This reflects higher wear during the initial running-in/tribofilm forming period. Exceptions are ZDDP, where a thick tribofilm is formed extremely rapidly, which effectively prevented runningin, TPPT and ADTP + TiPO. For the last of these the film formed appeared to be abrasive, as evidenced by the uneven interference fringes in the inlet and outlet regions in Fig. 9. Their lack of circularity indicates the presence of grooves

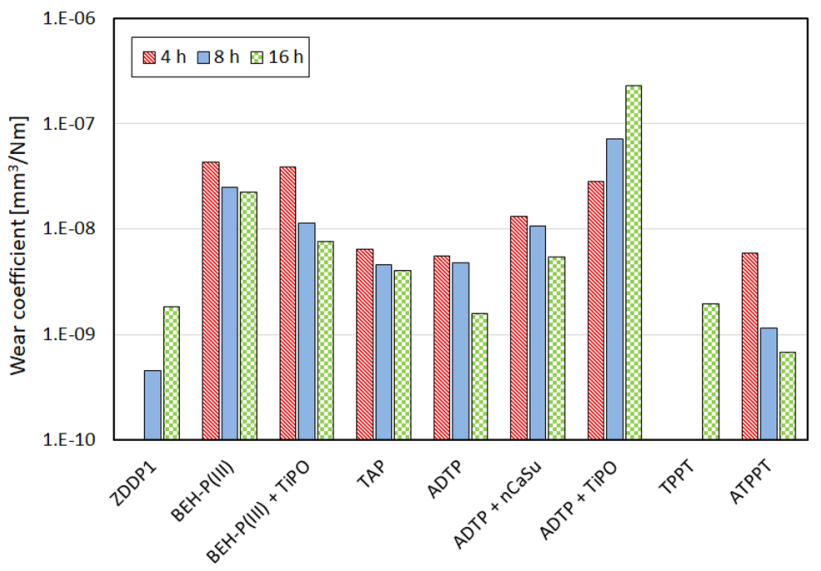

Fig. 16 Summary of wear rates for additive solutions after $4 \mathrm{~h}, 8 \mathrm{~h}$ and $16 \mathrm{~h}$ tests. Results are shown for the ends of the stroke

in the ball surface; a similar effect is seen in with nCaSu. From Fig. 16 it is evident that three additives, BEH-P(III), TAP and ADTP, give a wear rate about 50 to $100 \%$ greater than ZDDP, while TPPT is similar to ZDDP. ATPPT gives slightly lower wear rate than ZDDP after initial tribofilm formation while ADTP gives about the same long term wear rate as ZDDP. Addition of metallic ions to the system are harmful with the ashless P/S additive ADTP.

\section{Surface Characterisation Results}

Figure 17 shows AFM topography images of $25 \mu \mathrm{m} \times 25 \mu \mathrm{m}$ regions of the tribofilm in the wear scar on the disc for some of the ashless additives tested. Images of all the other additive solutions are included in the Appendix. It should be noted that the height scales are different for the various additive solutions and in all images the sliding direction is shown by a black arrow. BTPPT and Tri-iP-P(V) form padstructured tribofilms similar to that of ZDDP, while ATPPT forms a very different morphology, with flake-like structures some $100 \mathrm{~nm}$ thick. Although SLIM suggests that the film formed by PS is very thin, AFM reveals smooth parallel ridges along the rubbing direction that partially overlay polishing marks. The other alkyl phosphite and phosphate ester tribofilms all showed a pad-like structure with approximately the same pad size as ZDDP, typically 1 to 3 um in diameter, while AP, APT and TPPT all showed very directional films consisting of ridges in the rubbing direction forms a strongly 
directional film. TAP blend showed very thin and even film formation except for one very thick film ridge.

Reference XANES spectra together with the P K-edge FY and S K-edge FY spectra of the ZDDP tribofilm are included in the Appendix. ZDDP forms the expected zinc phosphates and polyphosphates of various chain lengths together with some Fe-containing species, i.e. $\mathrm{Fe}\left(\mathrm{PO}_{3}\right)_{3}, \mathrm{FePO}_{4}$ and $\mathrm{Fe}_{4}\left(\mathrm{P}_{2} \mathrm{O}_{7}\right)_{3}$. Zinc and iron sulphides were also detected.

Figure 18 shows the XANES P L-edge FY and P-K-edge FY spectra of the additives BEH-P(III), BEH-P(III) + TiPO and TAP tribofilms, together with spectra of the additives themselves and relevant reference compounds. The L-edge spectra probe ca $50 \mathrm{~nm}$ while the K-edge probe through to the tribofilm-steel interface. The bulk of the tribofilms comprise phosphite, probably from additive decomposition, phosphate and $\mathrm{Fe}$ polyphosphate, e.g. $\mathrm{Fe}_{10} \mathrm{P}_{18} \mathrm{O}_{55}$. The interface consists of a mixture of $\mathrm{Fe}-\mathrm{P}$-containing species i.e. $\mathrm{Fe}\left(\mathrm{PO}_{3}\right)_{3}, \mathrm{FePO}_{4}, \mathrm{Fe}_{4}\left(\mathrm{P}_{2} \mathrm{O}_{7}\right)_{3}, \mathrm{Fe}_{10} \mathrm{P}_{18} \mathrm{O}_{55}$.

Figure 19 shows XANES spectra of the surface/near surface, i.e. $\approx 5 \mathrm{~nm}$, and indicates the presence of phosphate, Fe polyphosphate, i.e. $\mathrm{Fe}_{10} \mathrm{P}_{18} \mathrm{O}_{55}$, sulphite and $\mathrm{FeSO}_{4}$. The composition of the bulk of the tribofilm through the interface film-steel, illustrated in Fig. 20 and comprises a mixture of $\mathrm{Fe}-\mathrm{P}-$ and $\mathrm{Fe}-\mathrm{S}$-containing species, i.e. $\mathrm{Fe}\left(\mathrm{PO}_{3}\right)_{3}, \mathrm{FePO}_{4}$, $\mathrm{Fe}_{4}\left(\mathrm{P}_{2} \mathrm{O}_{7}\right)_{3}, \mathrm{Fe}_{10} \mathrm{P}_{18} \mathrm{O}_{55}, \mathrm{FeSO}_{4}$, sulphite, $\mathrm{FeS}_{2}$, organic sulphide and disulphide.

XANES spectra of some of the other P/S additives are included in the Appendix.

Figure 21 shows TOF-SIMS surface imaging maps of various positive and negative ions from a disc surface rubbed in a solution of ADTP $+\mathrm{nCaSu}$. The rubbed track lies across
Fig. 17 AFM topography images of tribofilms formed by ashless additives. $25 \times 25 \mu \mathrm{m}$ scans
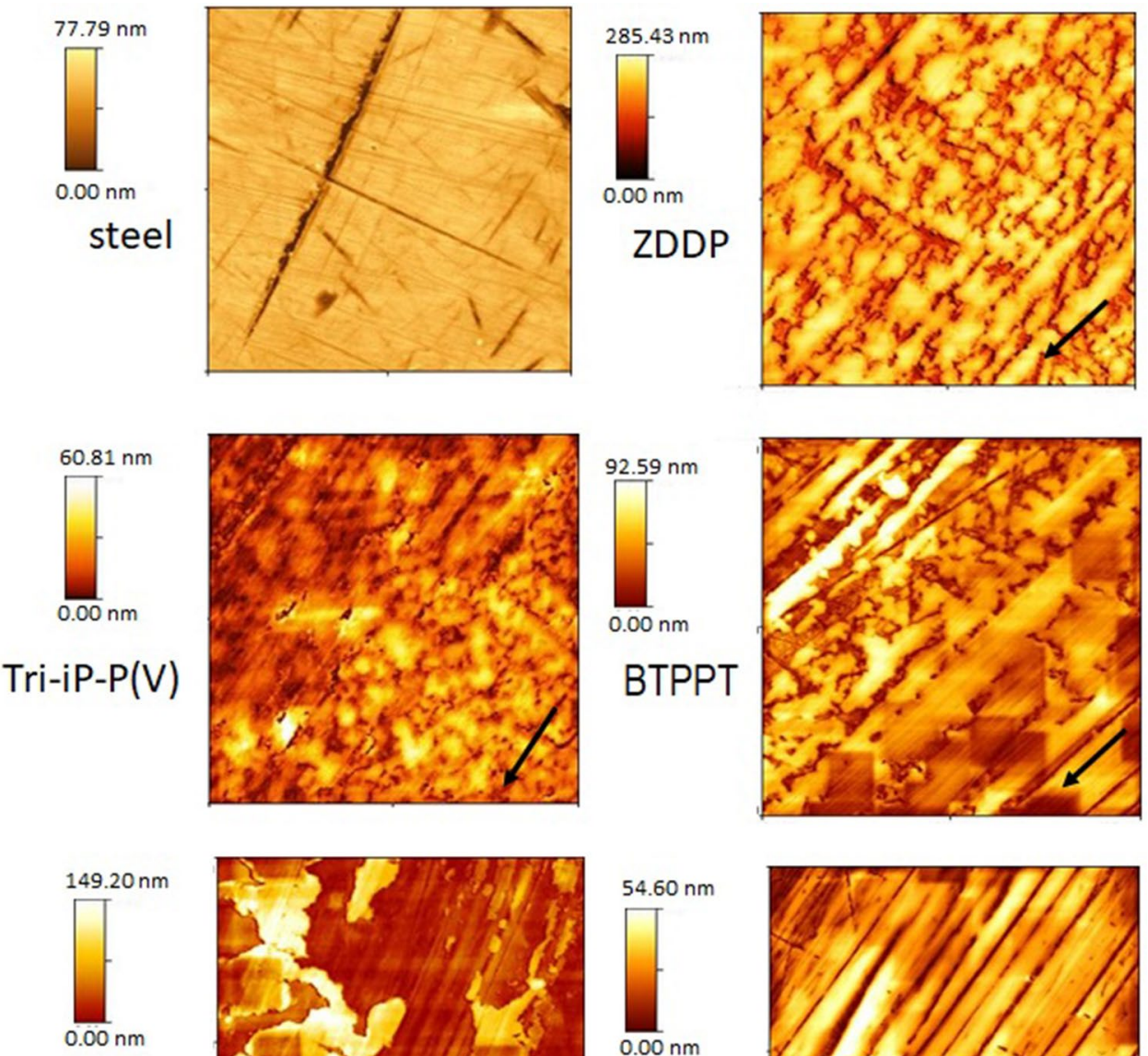

ATPPT

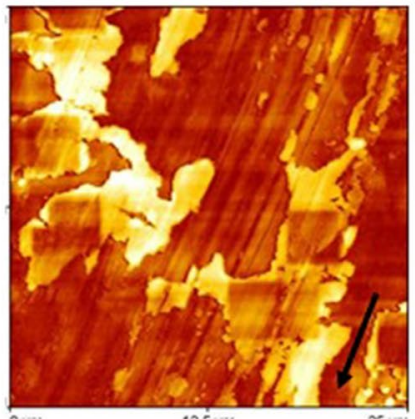

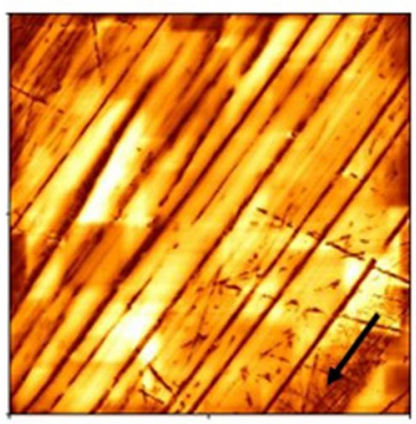



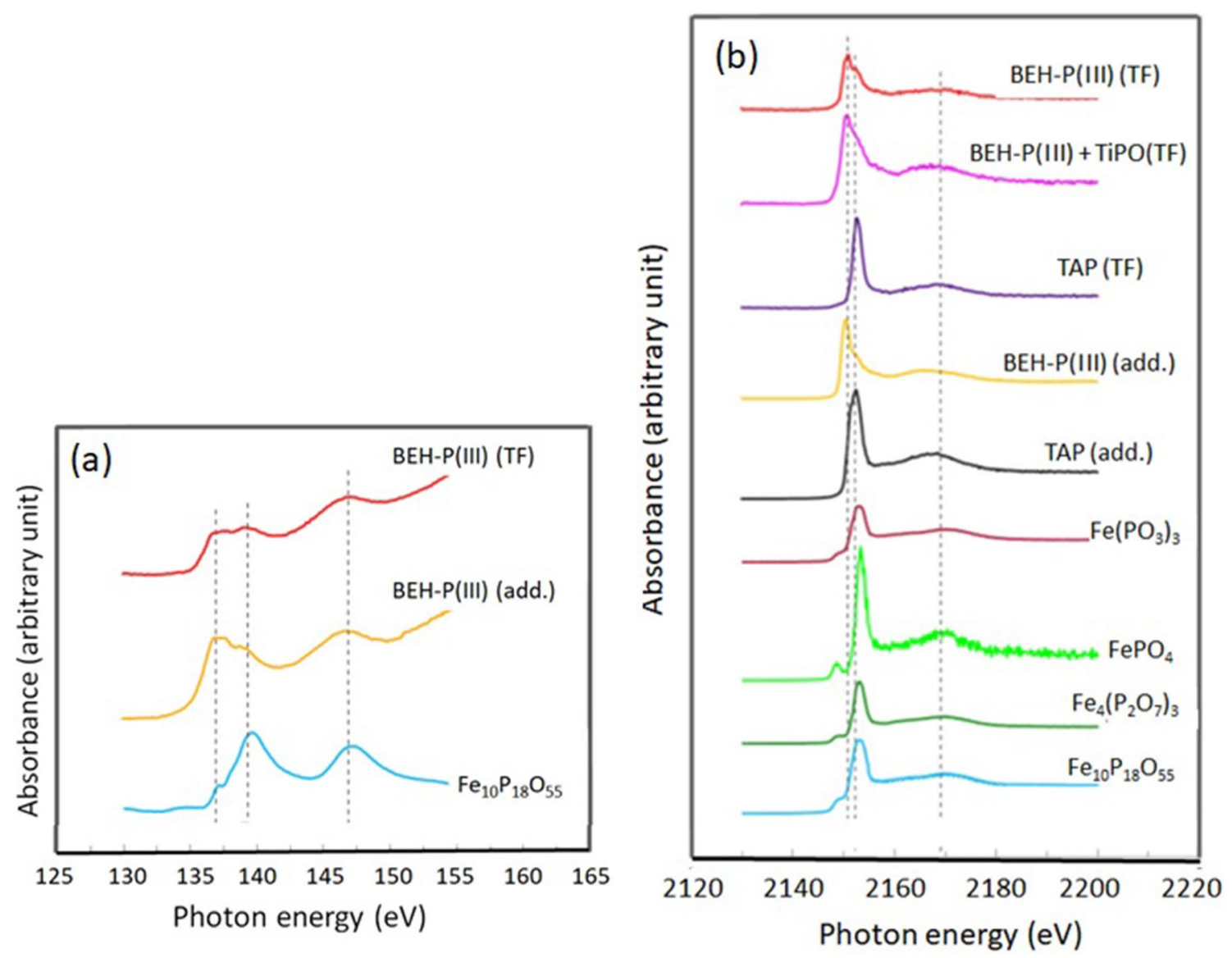

Fig. 18 XANES spectra of tribofilms formed by BEH-P(III), BEH-P(III) + TiPO and TAP, together with corresponding fresh additives and model compounds: a phosphorus L-edge FY $(\approx 50 \mathrm{~nm})$ and b phosphorus K-edge $\mathrm{FY}(>5 \mu \mathrm{m})$
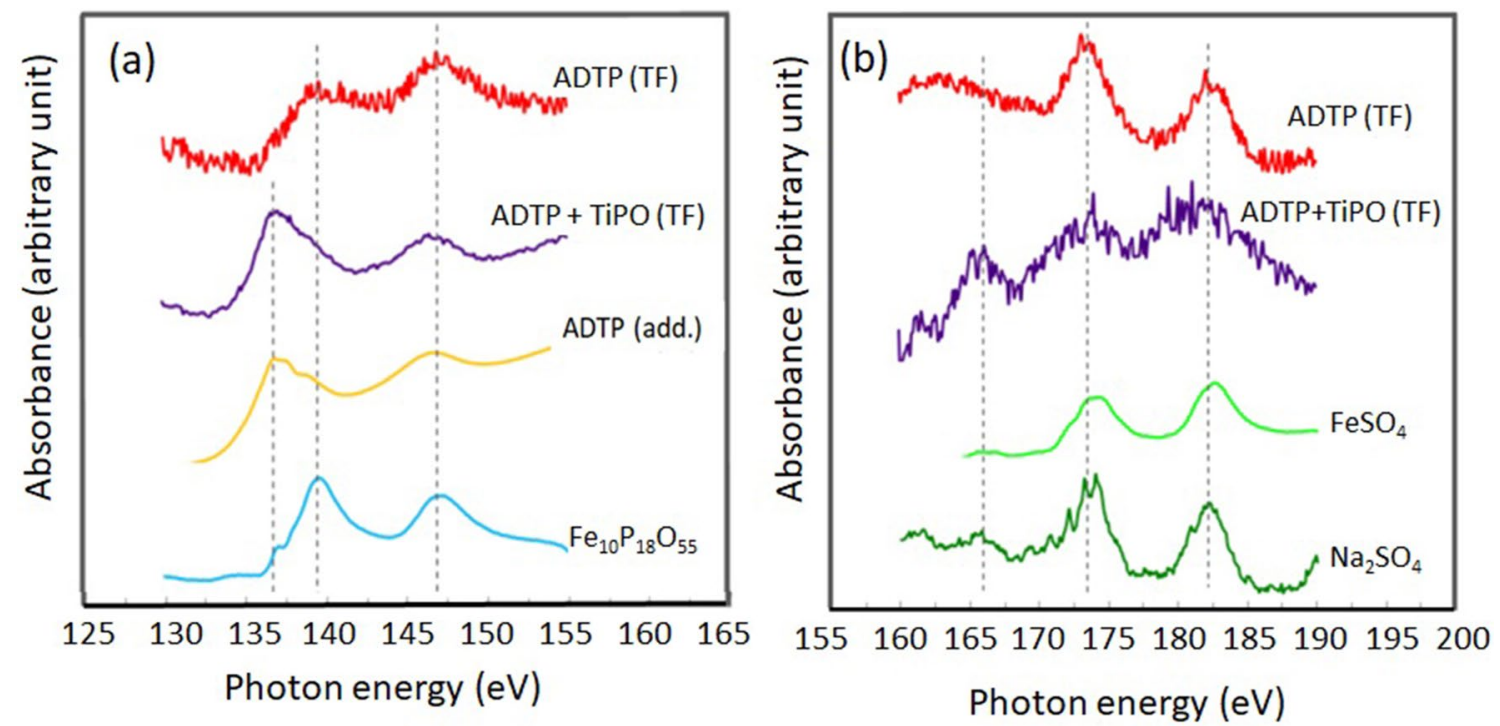

Fig. 19 XANES spectra of tribofilms formed by ADTP, ADTP + TiPO, corresponding fresh additives and model compounds: a phosphorus L-edge TEY $(\approx 5 \mathrm{~nm})$ and b sulphur L-edge TEY $(\approx 5 \mathrm{~nm})$ 

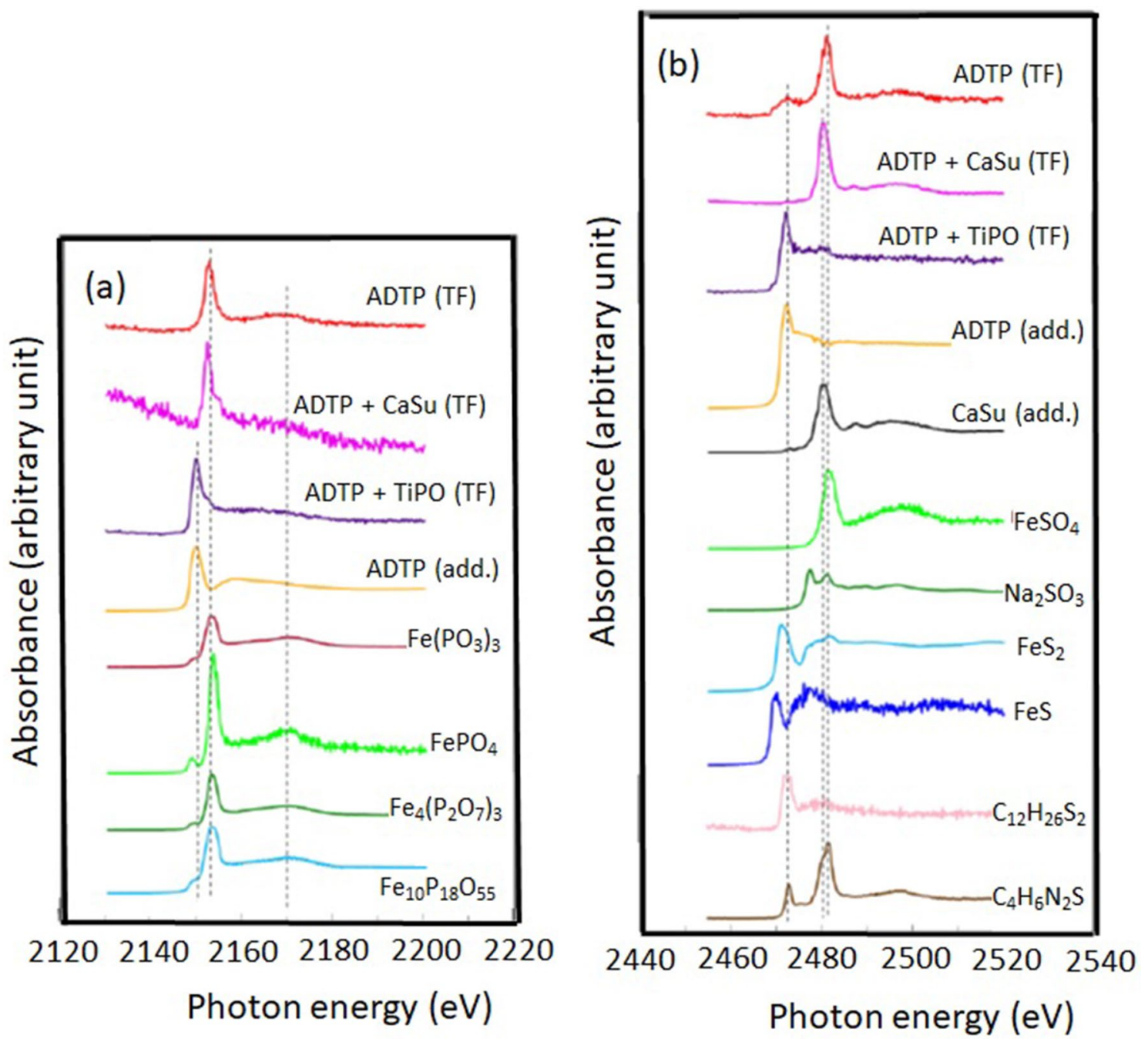

Fig. 20 XANES spectra of tribofilms formed by ADTP, ADTP + nCaSu, ADTP + TiPO, corresponding fresh additives and model compounds: a phosphorus K-edge FY $(>5 \mu \mathrm{m})$ and b sulphur K-edge FY $(>5 \mu \mathrm{m})$

the central region of the images. The track contains very high concentration of $\mathrm{PO}$ species with some sulphide and SO. There is considerable $\mathrm{Ca}$ in the film and much smaller levels of Fe. It is important to note that this TOF-SIMS analysis is very surface specific and only provides an indication of the chemical content of the uppermost few monolayers of film.

TOF-SIMS analysis of surfaces rubbed in ADTP+TiPO showed Ti similarly incorporated into the tribofilm surfaces [48]

\section{Discussion}

This study has confirmed the ability of ZDDP to form thick tribofilms on rubbing AISI 52100 steel surfaces, as well as previous observations that ashless $\mathrm{P}$ and $\mathrm{P} / \mathrm{S}$ additives form much thinner films than ZDDP under comparable conditions. Most of the ashless additives studied also form tribofilms more slowly than ZDDP, although the two phosphites appear to form them almost as fast, though the final films 

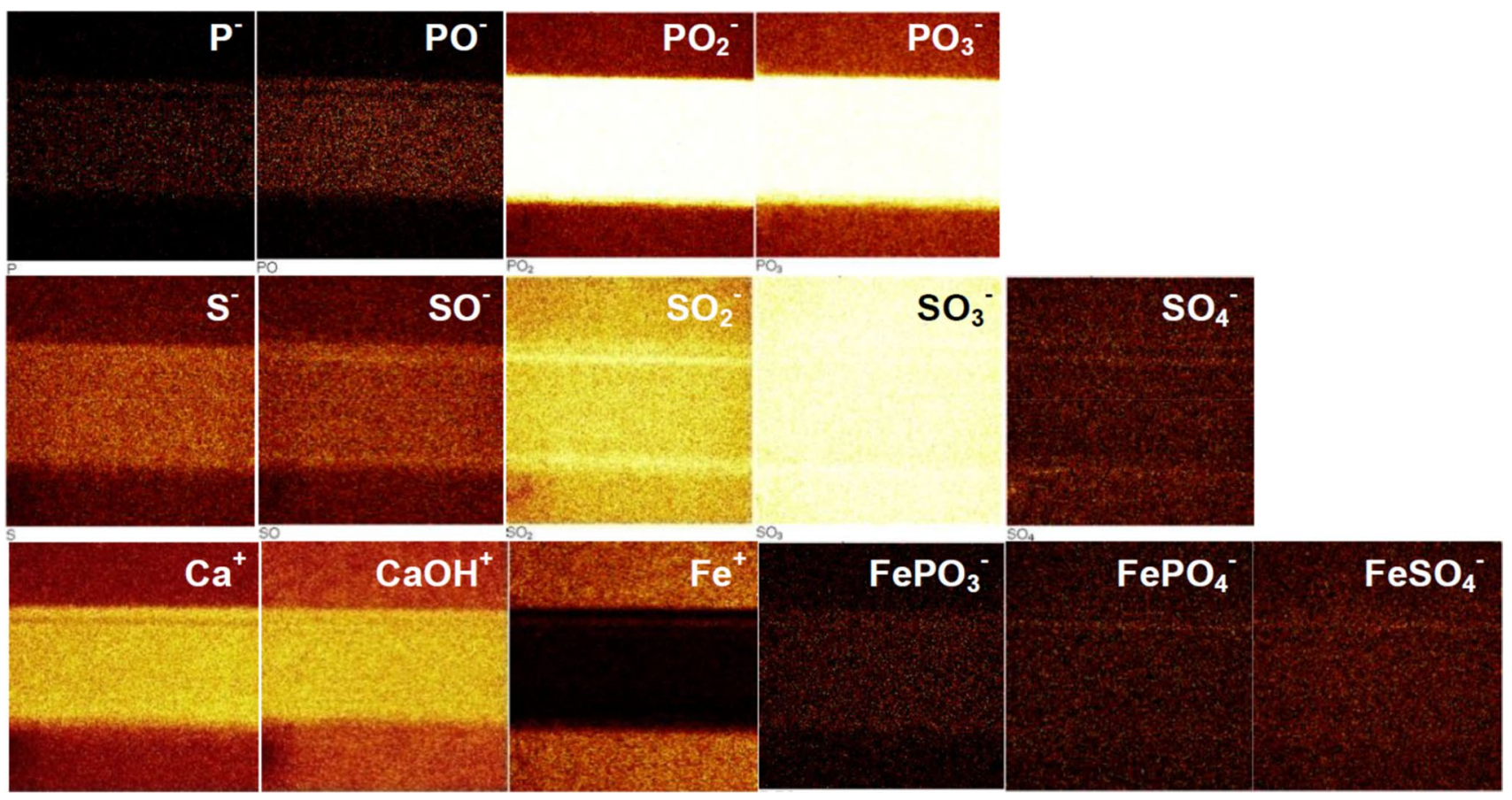

Fig. 21 TOF-SIMS analysis of disc surface rubbed in ADTP $+\mathrm{nCaSu}$

formed are much thinner. This is consistent with other studies that have found that the dialkyl and diaryl-phosphites (phosphonates) are more reactive than the corresponding phosphates. In general, the P/S-based ashless additives form thinner films than the $\mathrm{P}$ ones, perhaps reflecting a lower corrosivity and thus lower iron cation generation. The addition of two oil-soluble metal-containing supplements, one based on $\mathrm{Ti}$ and one on $\mathrm{Ca}$, both enhance the ability of the two ashless additives studied to form thick tribofilms. The titanium isopropoxide in particular leads the rapid formation of very thick films, comparable to those formed by ZDDP.

In terms of friction, some of the ashless additives give much lower boundary friction than ZDDP, in particular TAP, PS and PNS. However, most of the additives do not show the marked increase in mixed friction characteristic of ZDDP, which is believed to result from the rough topography of ZDDP's tribofilms. One exception is BEH-P(V), that shows a very similar Stribeck curve after rubbing to that of ZDDP. Figure 21 shows an AFM of the tribofilm formed by this additive, confirming that it is relatively rough.

Addition of supplementary soluble metal promotes film growth and, as illustrated in Fig. 14, this is reflected in the friction curves that show an extension of the boundary friction regime to higher entrainment speed.

In terms of wear, the P/S ashless additives give considerably lower wear than the P-ashless ones; (the logarithmic scale used in Fig. 16 obscures this difference to some extent). Indeed, based on $16 \mathrm{~h}$ wear tests the three P/S additives tested, ADTP, TPPT and ATPPT give as low wear as
ZDDP. It is noteworthy that if short tests are employed, two of the above additives do not appear to be as effective as ZDDP. This reflects the very rapid tribofilm formation of ZDDP. It can be conjectured that historically ZDDP has appeared such an effective antiwear additive in part because its performance tended to be measured in quite short tests, such as the one hour ASTM D4172 four-ball wear test, where an additive that forms films very rapidly to supress initial wear will excel. Such an ability is, however, arguably not relevant in engine use, where mild wear over prolonged operation is the main concern. Indeed, as discussed earlier in this paper, an additive that forms tribofilms very rapidly such as ZDDP will suppress running-in and thus promote micropitting.

Surface analysis broadly confirms previous work indicating that the $\mathrm{P}$ and $\mathrm{P} / \mathrm{S}$ additives form iron phosphates and polyphosphates, indicating reaction pathways that are roughly similar to those of ZDDP, albeit relying on the ferrous substrate to provide the cations needed to stabilise the anionic phosphate species. Likewise the detection of iron disulphide and organic sulphides with the P/S additives matches species found using XANES with ZDDP.

In determining the mechanism, or mechanisms, by which TiPO and $\mathrm{nCaSu}$ promote tribofilm formation a key question is whether titanium and calcium are incorporated into the tribofilm. Based on TOF-SIMS, Fig. 21 shows that $\mathrm{Ca}$ is present in the rubbed track from $\mathrm{ADTP}+\mathrm{nCaSu}$ while tests with ADTP TiPO and BEH-P-(III) + TiPO identified Ti within the rubbed track but not outside it [48]. However 
TOF-SIMS only analyses the first one or two monolayers of the surfaces and does not indicate composition deeper into the film.

Guevremont [55] et al. studied the tribological impact of an unidentified oil soluble Ti additive, probably a derivative of TiPO [56], in formulated oils containing ZDDP. XANES analysis identified Ti within the tribofilm and the authors suggested that this was incorporated in the iron oxide layer, possibly as a mixed oxide. Najman et al. used XPS and XANES to analyse the tribofilms formed by a combination of neutral calcium sulphonate and two ashless dithiophosphates, similar to the ones studied in the current work [57]. They identified Ca incorporated into the tribofilm, primarily close to the latter's surface and proposed that this was associated primarily with polyphosphate and that deeper regions of the film were predominantly iron phosphate. Based on this, the most likely contribution of TiPO and $\mathrm{nCaSu}$ is that they provide stabilising cations that augment $\mathrm{Fe}$ in forming polyphosphates or phosphates in the tribofilm and thereby accelerate their formation; it has been suggested that ashless additives form tribofilms more slowly than ZDDP because they must generate Fe cations by wear in order to develop a phosphate film [46]. However other mechanism, such as direct interactions of the additives with metal ions in solution cannot be ruled out.

Overall it is evident from this study that antiwear additives do not need to form very thick tribofilms like ZDDP in order to control wear effectively, although some measureable tribofilm formation ( 20 to $50 \mathrm{~nm}$ ) may be necessary. As shown in Fig. 16, the addition of supplementary metal species to enhance tribofilm thickness did not lead to a corresponding reduction in wear, indeed, for ADTP quite the contrary.

This study suggests that P/S-based alternatives to ZDDP in terms of friction and wear performance may be feasible. Of course this does not take into account volatility, and it might be anticipated that metal-free additives would be more
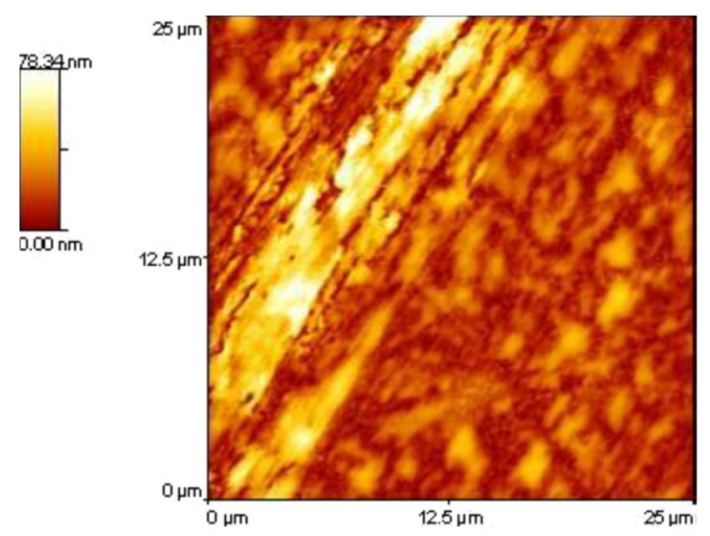

Fig. 22 AFM topography image of tribofilm formed by BEH-P(V) volatile than metal-containing ones of comparable polarity and molecular weight. Unfortunately very little appears to have been published concerning the volatility of ashless antiwear additives although Ribeaud has suggested that phosphorus emission from some ashless P-additives, were acceptable and comparable to ZDDP [58].

\section{Conclusions}

The film-forming, friction and wear properties of several ashless $\mathrm{P}$ and $\mathrm{P} / \mathrm{S}$ potential antiwear additives have been studied in rolling-sliding contact conditions. A method has been developed for removing the tribofilms formed by such additives in order to effectively quantify mild wear. In general the $\mathrm{P} / \mathrm{S}$ additives studied formed thinner tribofilms but gave lower wear than the S-free P ones. In extended wear tests, three $\mathrm{P} / \mathrm{S}$ additives gave wear as low, or lower, than a primary ZDDP. For almost all lubricants tested, the wear rate measured in short tests is considerably higher than that in long tests due to the greater contribution of running-in wear in the former. This highlights the importance of basing antiwear additive choice on reasonably long tests where running-in becomes only a small component of the wear measured. It has been found that for both $\mathrm{P}$ and $\mathrm{P} / \mathrm{S}$ ashless additives the addition of oil-soluble metal compounds based on $\mathrm{Ti}$ and $\mathrm{Ca}$ boosts tribofilm formation and can lead to very thick films, comparable to those formed by ZDDP. However, this thick film formation tends to be accompanied by an increase in mixed friction, and also does not appear to reduce wear and may increase it.

From this study it is evident that some P/S ashless additives can provide comparable antiwear protection for ZDDP for the system studied and may thus provide a means of reducing sulphated ash content in future engine oils (Fig. 22).

Acknowledgements The authors thank BP Castrol Ltd. for their kind support that enabled the research described in this article to be carried out. We are also very grateful to Maura Crobu for supply of the zinc phosphate reference specimens.

Open Access This article is licensed under a Creative Commons Attribution 4.0 International License, which permits use, sharing, adaptation, distribution and reproduction in any medium or format, as long as you give appropriate credit to the original author(s) and the source, provide a link to the Creative Commons licence, and indicate if changes were made. The images or other third party material in this article are included in the article's Creative Commons licence, unless indicated otherwise in a credit line to the material. If material is not included in the article's Creative Commons licence and your intended use is not permitted by statutory regulation or exceeds the permitted use, you will need to obtain permission directly from the copyright holder. To view a copy of this licence, visit http://creativecommons .org/licenses/by/4.0/. 


\section{Appendix}

See Figs. 23, 24, 25, 26, 27, 28, and 29.

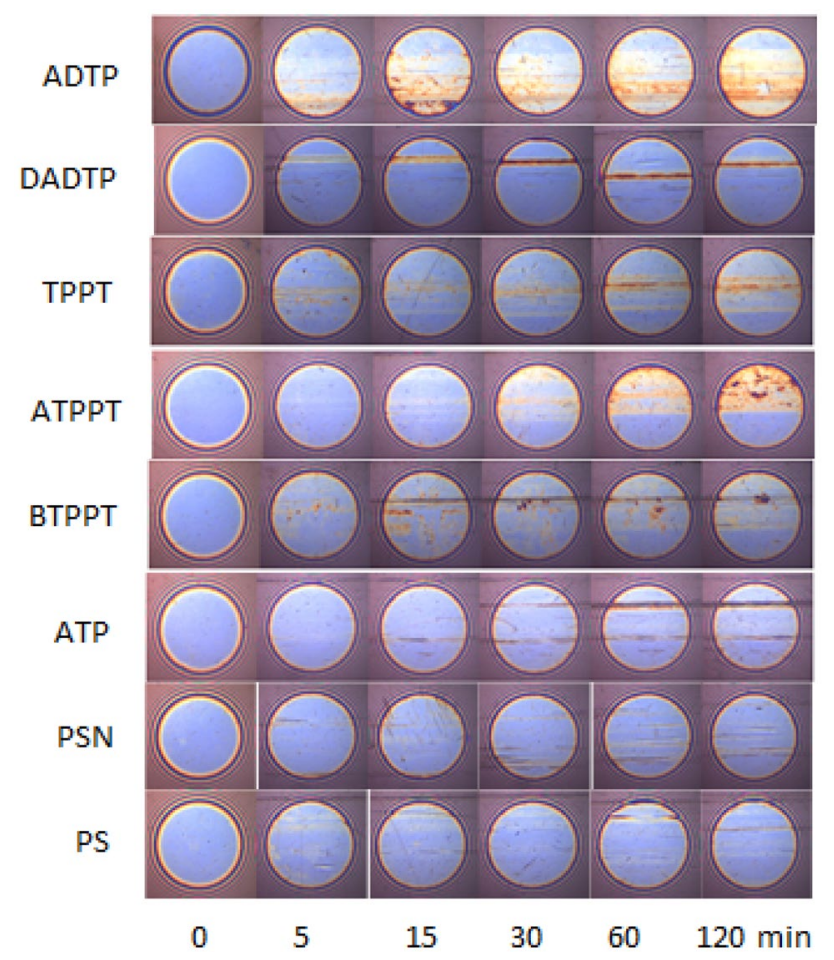

Fig. 23 SLIM images of tribofilms formed by P/S additive solutions
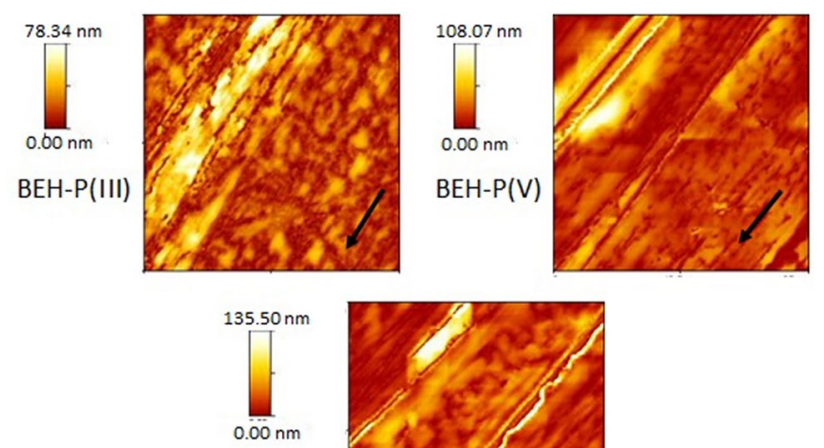

Tri-iP-P(III)
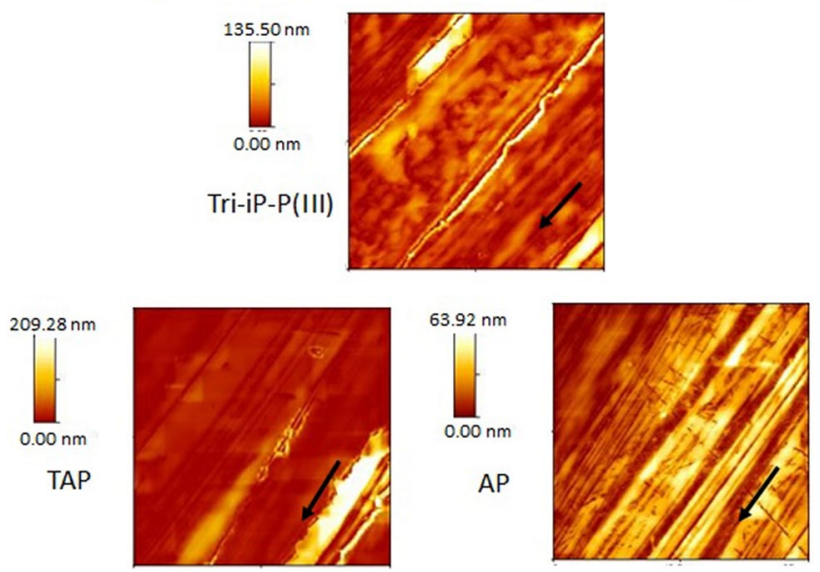

Fig. 24 AFM topography images of P-additive tribofilms. $25 \times 25 \mu \mathrm{m}$ scans
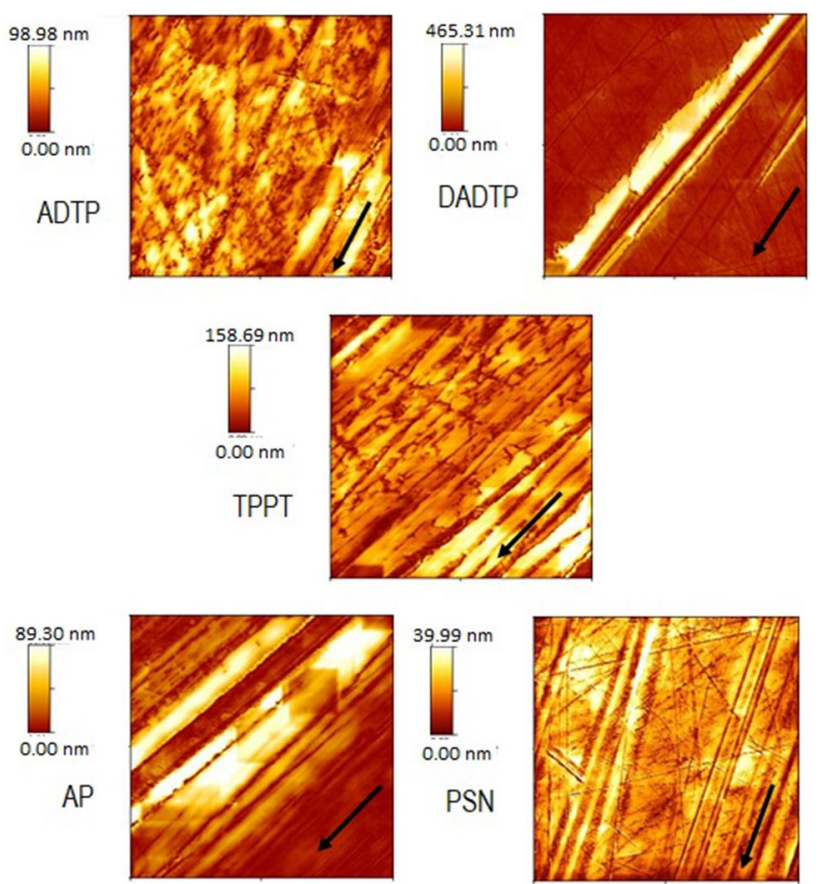

Fig. 25 AFM topography images of P-S additive tribofilms. $25 \times 25$ $\mu \mathrm{m}$ scans 

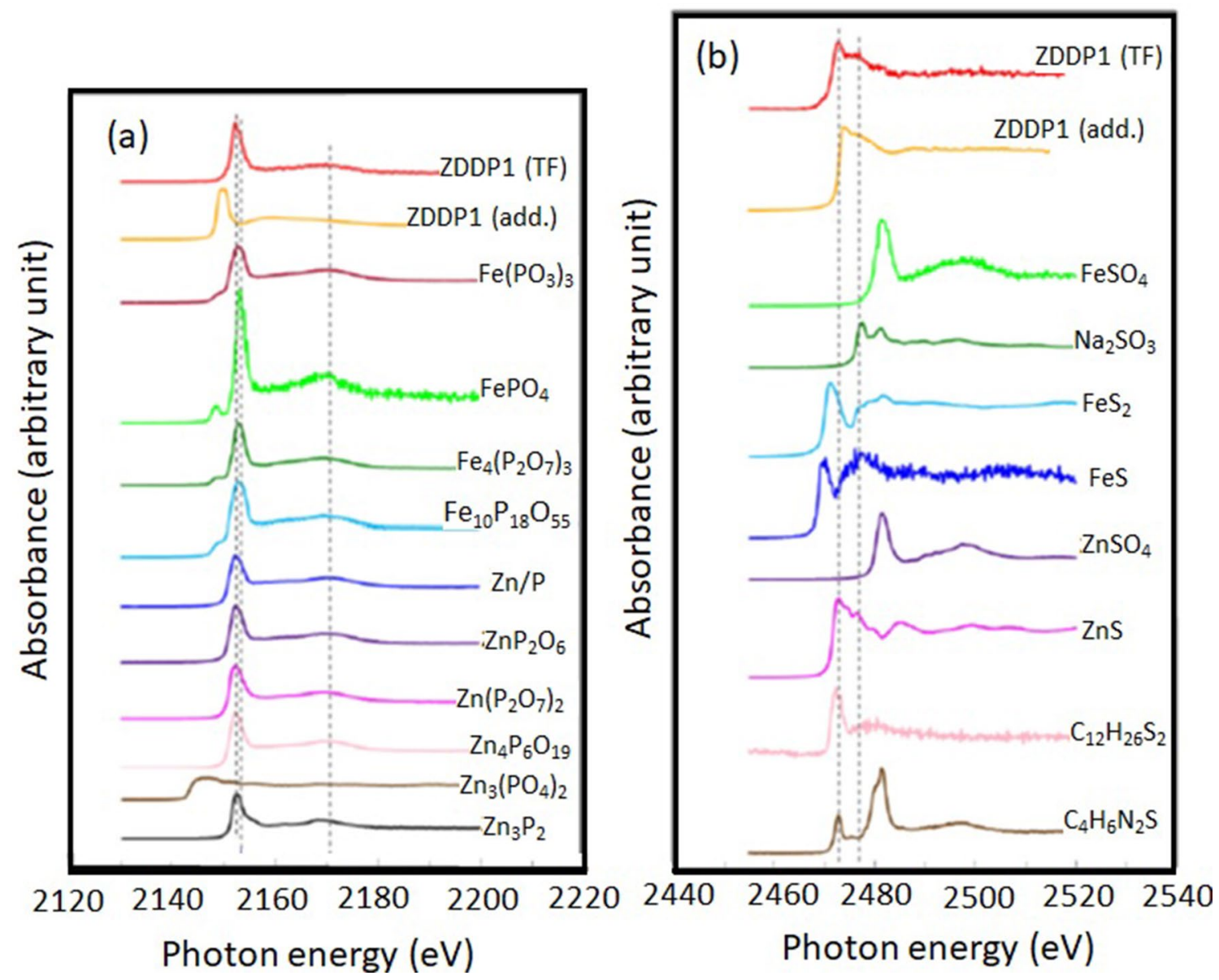

Fig. 26 XANES spectra of ZDDP1 and model compounds. a P K-edge FY (bulk through the film to substrate >5 $\mu$ m); b S K-edge FY (bulk through the film to substrate $>5 \mu \mathrm{m}$ )

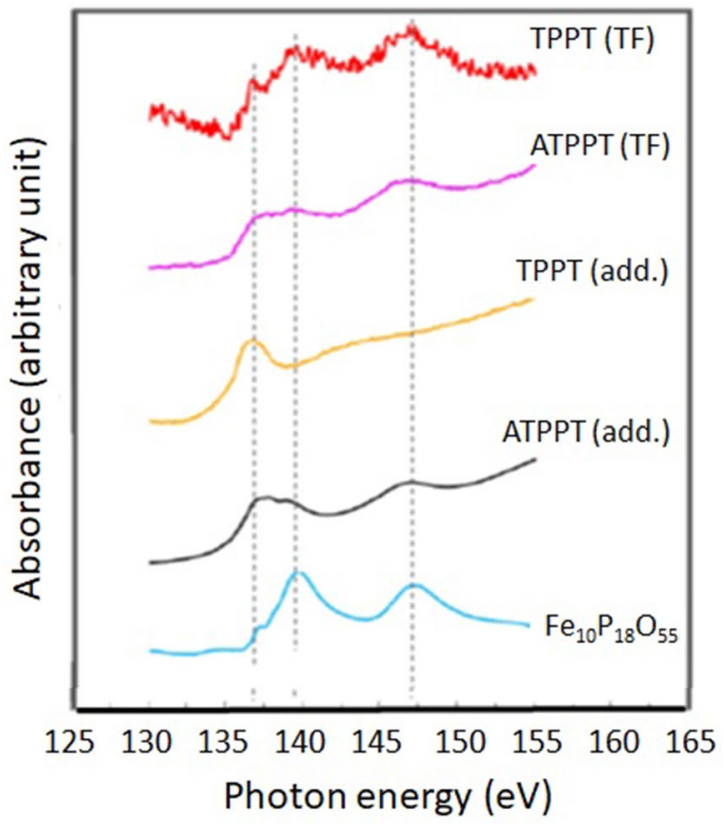

Fig. 27 XANES spectra of tribofilms formed by TPPT and ATPPT. P L-edge TEY (surface/near surface $\sim 5 \mathrm{~nm}$ ) 

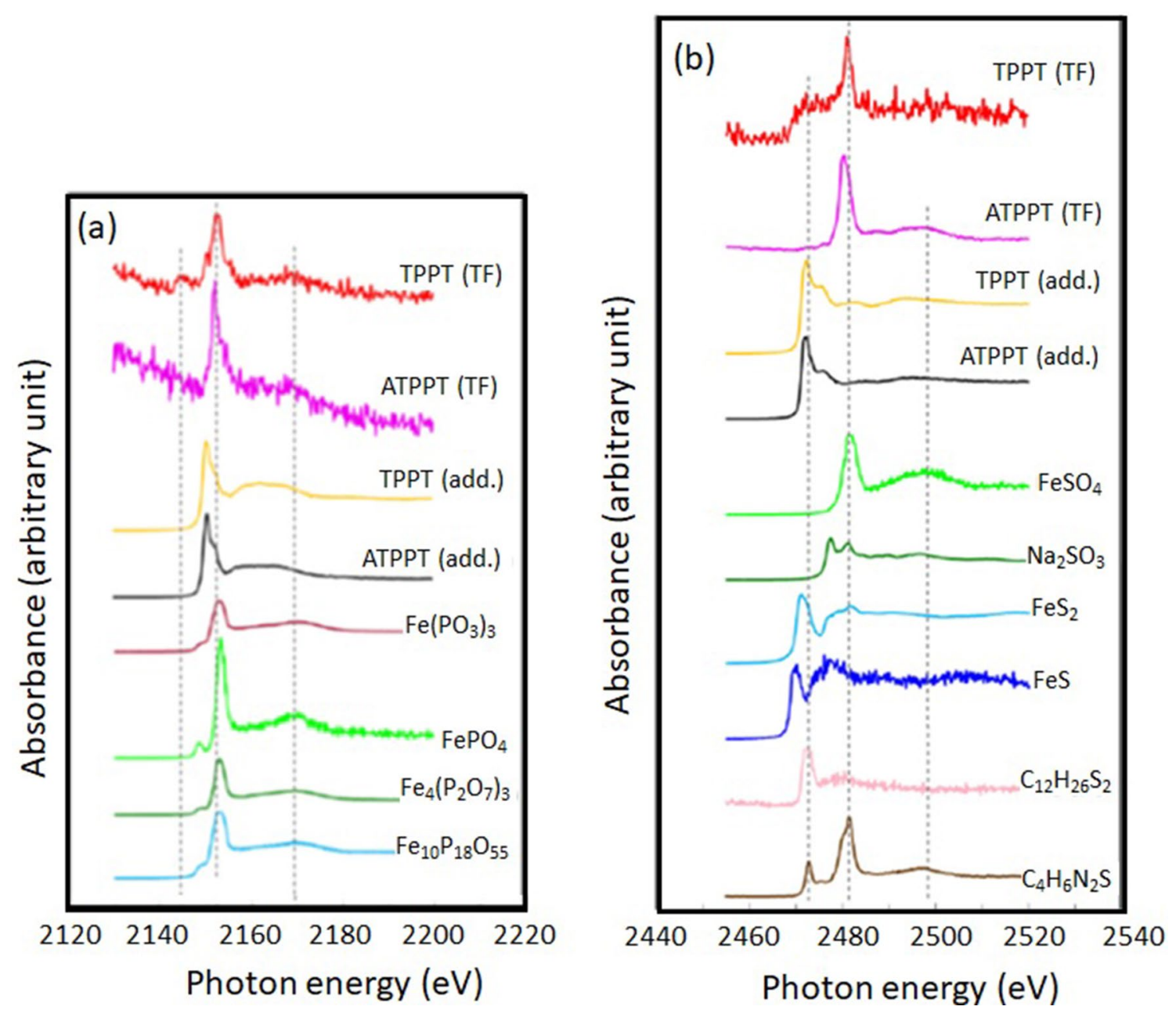

Fig. 28 XANES spectra TPPT, ATPPT and model compounds. a P K-edge FY (bulk through the film to substrate $>5 \mu \mathrm{m}$ ); b S K-edge FY (bulk through the film to substrate $>5 \mu \mathrm{m}$ ) 

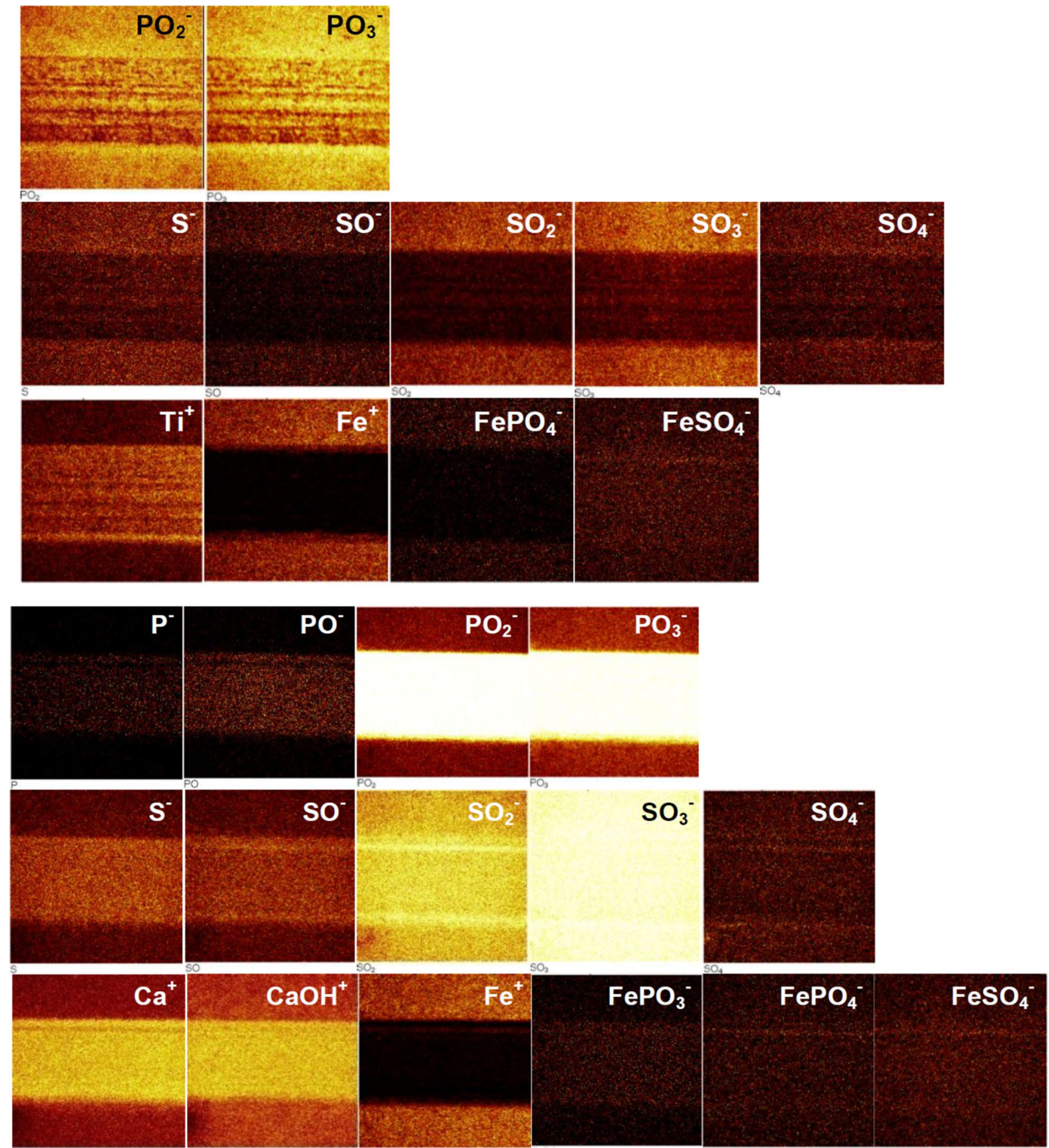

Fig. 29 TOF-SIMS images of ion distributions from disc surface in and around the rubbed track from MTM tests with ADTP + TiPO solution 


\section{References}

1. Spikes, H.A.: The history and mechanisms of ZDDP. Tribol. Lett. 17, 465-485 (2004)

2. Williamson W.B., Perry J., Goss R.L., Gandhi H.S., Beason R.E.: Catalyst deactivation due to glaze formation from oil-derived phosphorus and zinc. SAE Techn. Paper 841406, (1984)

3. Bodek, K.M., Wong, V.V.: The effects of sulfated ash, phosphorus and sulfur on diesel aftertreatment systems - a review. SAE Techn. Paper 2007-01-1922, (2007)

4. ILSAC GF-5 Standard for Passenger Car Engine Oil. (2009). Available from: https://www.ilma.org.

5. Waddey, W.E., Shaub, H., Pecoraro, J.M, Carley, R.A.: Improved fuel economy via engine oils. SAE Techn. Paper 78059, (1978)

6. Bovington, C. Anghel, V., Spikes, H.A.: Predicting sequence VI and VIA fuel economy from laboratory bench tests. SAE Techn. Paper 961142, (1996)

7. Dawczyk, J., Morgan, N., Russo, J., Spikes, H.A.: ZDDP tribofilm in rolling-sliding contact. Tribol. Lett. 67, 34 (2019)

8. Benyajati, C., Olver, A.V., Hamer, C.J.: An experimental study of micropitting, using a new miniature test-rig. Tribol Series $\mathbf{4 3}$, 601-610 (2003)

9. Laine, E., Olver, A.V., Beveridge, T.A.: Effect of lubricants on micropitting and wear. Tribol. Intern. 41, 1049-1055 (2008)

10. Liu, H., Liu, H., Zhu, C., Zhou, Y.: A review on micropitting studies of steel gears. Coatings 9, 42-68 (2019)

11. Ueda, M., Spikes, H.A., Kadiric, A.: In-situ observation of ZDDP tribofilm growth and its effect on micropitting. Tribol. Intern. 138, 342-352 (2019)

12. Spikes, H.A.: Low and zero-sulphated ash, phosphorus and sulphur anti-wear additives for engine oils. Lubr. Sci. 20, 1893-1901 (2008)

13. Peale, L.F., Messina, J., Ackerman, B., Sasin, R., Swern, D.: Evaluation of long-chain phosphorus compounds as lubricity additives. ASLE Trans. 3, 48-54 (1960)

14. Kerley, R.V.: A history of aircraft piston engine lubricants. SAE Techn. Paper 810849, (1981)

15. Mortier, R.M., Fox, M.F., Oszulik, S.T. (eds.): Chemistry and Technology of Lubricants, 3rd edn. Publ Springer, New York (2010)

16. Khorramian, B.A., Iyer, G.R., Kodali, S., Natarajan, P., Tupil, R.: Review of antiwear additives for crankcase oils. Wear 169, 87-95 (1993)

17. Papay, A.G.: Antiwear and extreme-pressure additives in lubricants. Lubr. Sci. 10, 209-224 (1998)

18. Johnson, D., Hils, J.: Phosphate esters, thiophosphate esters and metal thiophosphates as lubricant additives. Lubricants 1, 132148 (2013)

19. Guan, B., Pochopien, B.A., Wright, D.S.: The chemistry, mechanism and function of tricresyl phosphate (TCP) as an anti-wear lubricant additive. Lubr. Sci. 28, 257-265 (2016)

20. Beeck, O., Givens, J.W., Williams, E.C.: On the mechanism of boundary lubrication. II. Wear prevention by addition agents. Proc. R. Soc. Lond. Ser A 177, 103-118 (1940)

21. Barcroft, F.T., Daniel, S.G.: The action of neutral organic phosphates as EP additives. Trans. ASME J. Basic Eng. 87, 761-767 (1965)

22. Godfrey, D.: The lubrication mechanism of tricresyl phosphate on steel. Wear 8, 1-11 (1965)

23. Faut, O.D., Wheeler, D.R.: On the mechanism of lubrication by tricresyl phosphate (TCP): the coefficient of friction as a function of temperature for TCP on M-50 steel. ASLE Trans. 26, 344-435 (1983)
24. Gauthier, A., Montes, H., Georges, J.M.: Boundary lubrication with tricresylphosphate (TCP) Importance of corrosive wear. ASLE Trans. 25, 445-455 (1982)

25. Forbes, E.S., Silver, H.B.: The effect of chemical structure on the load carrying properties of organo phosphorus compounds. J. Inst. Petrol. 57, 90-98 (1970)

26. Forbes, E.S., Neustadter, E.L., Silver, H.B., Upsdell, N.T.: The effect of chemical structure on the load-carrying properties of amine phosphates. Wear 18, 269-278 (1971)

27. Sakurai, T., Sato, K.: Chemical reactivity and load carrying capacity of lubricating oils containing organic phosphorus compounds. ASLE Trans. 13, 252-261 (1970)

28. Barber, R.I.: The preparation of some phosphorus compounds and their comparison as load-carrying additives by the four-ball machine. ASLE Trans. 19, 319-328 (1976)

29. Riga, A., Cahoon, J., Pistillo, W.R.: Organophosphorus chemistry structure and performance relationships in FZG gear tests. Tribol. Lett. 9, 219-225 (2000)

30. Minami, I., Hong, H.S., Mathus, N.C.: Effect of alkenes on the antiwear mechanism of dialkyl hydrogen phosphites. Lubr. Sci. 13, 219-230 (2001)

31. Klaus, E.E., Bieber, H.E.: Effect of P32 impurities on the behaviour of tricresylphosphate 32 as an antiwear additive. ASLE Trans. 8, 12-20 (1965)

32. Rounds, F.G.: Some environmental factors affecting surface coating formation with lubricating oil additives. ASLE Trans. 9, 88-100 (1966)

33. Forbes, E.S.: Battersby, J: The effect of chemical structure on the load-carrying and adsorption properties of dialkyl phosphites. ASLE Trans. 17, 263-270 (1974)

34. Lacey, I.N., Kelsall, G.H., Spikes, H.A.: Thick antiwear films in elastohydrodynamic contacts. Part I: film growth in rolling/sliding EHD contacts. ASLE Trans. 29, 299-305 (1986)

35. Lacey, I.N., Kelsall, G.H., Spikes, H.A.: Thick antiwear films in elastohydrodynamic contacts. Part II: chemical nature of the deposited films. ASLE Trans. 29, 306-311 (1985)

36. Cann, P.M., Johnston, G.J., Spikes, H.A.: The formation of thick films by phosphorus-based anti-wear additives. Proc. Inst. Mech. Eng. C208(87), 543-554 (1987)

37. Bertrand, P.A.: Reactions of tricresyl phosphate with bearing materials. Tribol. Lett. 3, 367-377 (1997)

38. Musselman, J.M.: Preparation of lubricants. U.S. Patent 2,383,495, (1945).

39. Schumacher, R., Zinke, H.: Tribofragmentation and antiwear behaviour of isogeometric phosphorus compounds. Tribol. Intern. 30, 199-208 (1997)

40. Zinke, H., Schumacher, R.: The thermal stability and antiwear performance of some thiophosphoric acid derivatives. Wear 179, 45-48 (1994)

41. Taylor, L., Glovnea, R., Ribeaud, M., Spikes, H.A: The nature and properties of antiwear additive films. In: Proceedings International Tribology Conference, Nagasaki Oct. 2000, vol. II, pp. 1257-1262. JST Tokyo (2001)

42. Rossi, A., Piras, F.M., Kim, D., Gellman, A.J., Spencer, N.D.: Surface reactivity of tributyl thiophosphate: effects of temperature and mechanical stress. Tribol. Lett. 23, 197-208 (2006)

43. Mangolini, F., Rossi, A., Spencer, N.D.: Tribochemistry of triphenyl phosphorothionate (TPPT) by in situ attenuated total reflection (ATR/FT-IR) tribometry. J. Phys. Chem. C 116, 5614-5627 (2012)

44. Borshchevskii, S.B., Levitina, I.S., Shabanova, E.V., Kotova, G.G.: Additives based on dithiophosphoric acids and unsaturated compounds for lubricating oils. Chem. Technol. Fuels Oils 27, 326-328 (1991)

45. Sharma, M., Bansai, V., Ray, S.S., Sarin, R., Tuli, D.K., Shainagar, A.K.: Role of alkyl moieties in the antiwear and antioxidant 
performance of alkyl phosphorodithiophosphates. Lubr. Sci. 15, 321-328 (2003)

46. Najman, M.N., Kasrai, M., Bancroft, G.M.: Chemistry of antiwear films from ashless thiophosphate oil additives. Tribol. Lett. 17, 217-229 (2003)

47. Kim, B., Mourhatch, R., Aswath, P.B.: Properties of tribofilms formed with ashless dithiophosphate and zinc dialkyl dithiophosphate under extreme pressure conditions. Wear 268, 579-591 (2010)

48. Benedet, J.: Low and zero SAPS antiwear additives for engine oils. $\mathrm{PhD}$ Thesis, Imperial College London, (2102)

49. Brow, R.K., Tallant, D.R., Myers, S.T., Phifer, C.C.: The shortrange structure of zinc polyphosphate glass. J. Non-Cryst. Solids 191, 45-55 (1995)

50. Benedet, J., Green, J.H., Lamb, G.D., Spikes, H.A.: Spurious mild wear measurement using white light interference microscopy in the presence of antiwear films. Tribiol Trans. 52, 841-846 (2009)

51. Panias, D., Taxiarchou, M., Paspaliaris, I., Kontopoulos, A.: Mechanisms of dissolution of iron oxides in aqueous oxalic acid solutions. Hydrometallurgy 42, 257-265 (1996)

52. Yamaguchi, E.S., Wilson, D.M., Kasrai, M., Bancroft, G.M.: XANES analysis of used engine oils and relationship to wear. Tribiol. Trans. 45, 437-443 (2002)
53. Crobu, M., Rossi, A., Mangolini, F., Spencer, N.D.: Tribochemistry of bulk zinc metaphosphate glasses. Tribol. Lett. 39(2), 121-134 (2010)

54. Crobu, M., Rossi, A., Mangolini, F., Spencer, N.: Chain-lengthidentification strategy in zinc polyphosphate glasses by means of XPS and ToF-SIMS. Anal. Bioanal. Chem. 403, 1415-1432 (2012)

55. Guevremont, J.M., Guinther, G.H., Szemenyei, D., Devlin, M.T., Jao, T.-C., Jaye, C., Woicik, J., Fischer, D.A.: Enhancement of engine oil wear and friction control performance through titanium additive chemistry. Tribiol. Trans. 51, 324-331 (2008)

56. Mathur, N.C., Guevremont, J.M.: Method for making a titaniumcontaining lubricant additive. U.S. Patent No. 8,008,237

57. Najman, M., Kasrai, M., Bancroft, G.M., Davidson, R.: Combination of ashless antiwear additives with metallic detergents: interactions with neutral and overbased calcium sulfonates. Tribol. Int. 39(4), 342-355 (2006)

58. Ribeaud, M.: Volatility of phosphorus-containing anti-wear agents for motor oils. Lubr. Sci. 18, 231-241 (2006)

Publisher's Note Springer Nature remains neutral with regard to jurisdictional claims in published maps and institutional affiliations. 